\title{
Review
}

\section{Diversity of human skeletal muscle in health and disease: Contribution of proteomics}

\author{
Cecilia Gelfi ${ }^{a, b, *}$, Michele Vasso ${ }^{a, b}$, Paolo Cerretelli ${ }^{b}$ \\ ${ }^{a}$ Dipartimento di Scienze e Tecnologie Biomediche, Università degli Studi di Milano, Milan, Italy \\ ${ }^{\mathrm{b}}$ Istituto di Bioimmagini e Fisiologia Molecolare, C.N.R., Segrate (Milan), Italy
}

\section{A R T I C L E I N F O}

\section{Article history:}

Received 16 December 2010

Accepted 26 February 2011

Available online 15 March 2011

\section{Keywords:}

Muscle

Proteomics

Mass spectrometry

DIGE

\begin{abstract}
A B S T R A C T
Muscle represents a large fraction of the human body mass. It is an extremely heterogeneous tissue featuring in its contractile structure various proportions of heavyand light-chain slow type 1 and fast types $2 \mathrm{~A}$ and $2 \mathrm{X}$ myosins, actins, tropomyosins, and troponin complexes as well as metabolic proteins (enzymes and most of the players of the so-called excitation-transcription coupling). Muscle is characterized by wide plasticity, i.e. capacity to adjust size and functional properties in response to endogenous and exogenous influences. Over the last decade, proteomics has become a crucial technique for the assessment of muscle at the molecular level and the investigation of its functional changes. Advantages and shortcomings of recent techniques for muscle proteome analysis are discussed. Data from differential proteomics applied to healthy individuals in normal and unusual environments (hypoxia and cold), in exercise, immobilization, aging and to patients with neuromuscular hereditary disorders (NMDs), inclusion body myositis and insulin resistance are summarized, critically discussed and, when required, compared with homologous data from pertinent animal models. The advantages as well as the limits of proteomics in view of the identification of new biomarkers are evaluated.
\end{abstract}

(c) 2011 Elsevier B.V. All rights reserved.

\section{Contents}

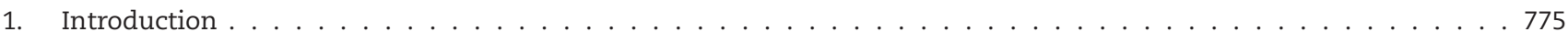

2. Some aspects of the plasticity of human muscle fibers . . . . . . . . . . . . . . . . . . . . . . . . . 775

2.1. Myosin heavy chain (MHC) isoforms and changes of MHC expression . . . . . . . . . . . . . . . . . . . 775

2.2. Myosin light chain polymorphism . . . . . . . . . . . . . . . . . . . . . . . . . 776

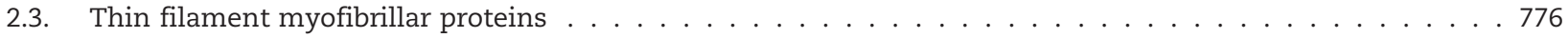

2.4. Muscle contractile protein-induced post-translational changes . . . . . . . . . . . . . . . . . . . . 777

2.5. Signaling molecules in pathways controlling muscle fiber size and type . . . . . . . . . . . . . . . . . . . 777

3. The contribution of proteomics to the study of human muscle . . . . . . . . . . . . . . . . . . . . . . . 777

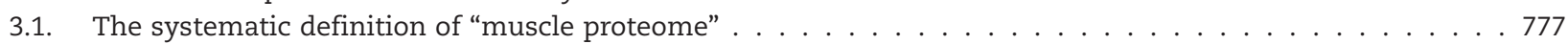

3.2. Post-translational modifications . . . . . . . . . . . . . . . . . . . . . . . . . 780

* Corresponding author at: Dipartimento di Scienze e Tecnologie Biomediche, Università degli Studi di Milano, Milan, Italy; Via Fratelli Cervi 93, 20090 Segrate, Milan, Italy. Tel.: +39 02 50330475; fax: +39 0221717558.

E-mail address: cecilia.gelfi@unimi.it (C. Gelfi). 
3.3. The proteomic profile of functional mitochondria . . . . . . . . . . . . . . . . . . . . . . . 780

4. Differential studies under physiological and paraphysiological conditions . . . . . . . . . . . . . . . . . . . 780

4.1. The proteome of muscle tissue under chronic and subacute hypoxia . . . . . . . . . . . . . . . . . . . . . 781

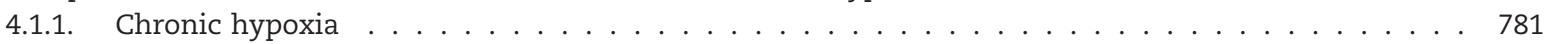

4.1.2. Subacute hypoxia . . . . . . . . . . . . . . . . . . . . . . . . 781

4.2. Differential proteomics of muscles from the same subject: Vastus lateralis us deltoideus . . . . . . . . . . . . 782

4.3. Metabolic response to cold and overfeeding . . . . . . . . . . . . . . . . . . . . . 783

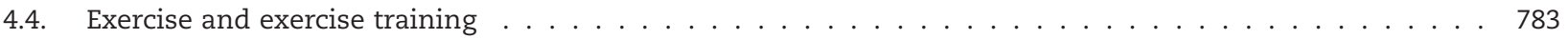

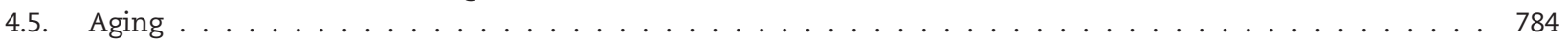

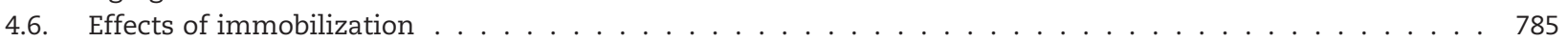

4.7. Effects of eccentric upper extremity exercise on plasma proteome . . . . . . . . . . . . . . . . 786

5. Differential proteomics in the study of muscle pathophysiology and pathology . . . . . . . . . . . . . . 786

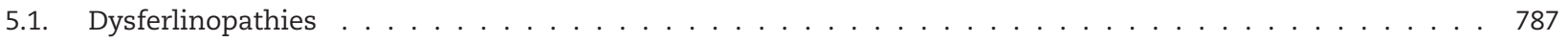

5.2. Facioscapulohumeral muscular dystrophy . . . . . . . . . . . . . . . . . . . . . . . . . . 787

5.3. Inclusion body myositis $(\mathrm{IBM}) \ldots \ldots \ldots \ldots$

5.4. Dermatomyositis with muscle perifascicular atrophy . . . . . . . . . . . . . . . . . . . . . . 789

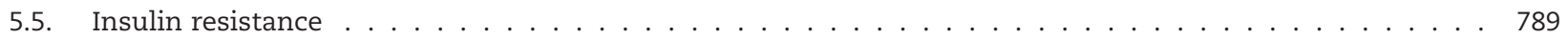

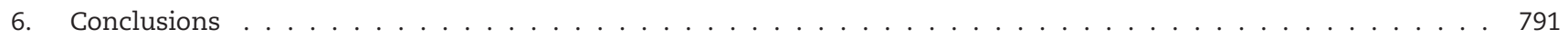

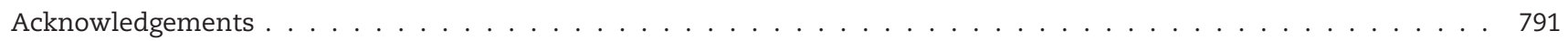

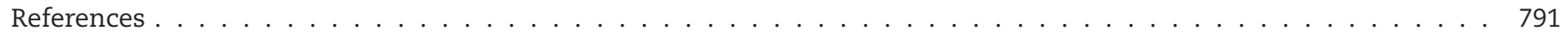

\section{Introduction}

The "plasticity" of skeletal muscle is the capacity to adjust size and functional properties of its fibers in response to endogenous and exogenous influences. Among the latter, the most effective are neural input as shown originally, in the cat, by Buller et al. [1] with the classic nerve cross-union experiments, mechanical loading, such as during resistance and endurance exercise and various other training protocols, inactivity, such as in forced bed rest, exposure to unusual environmental conditions (hypo- and hypergravity, cold and hypoxia), aging and the effects of a number of biochemical, trophic and hormonal variables [2,3]. Adaptive features, mainly mediated by altered gene expression but also by post-translational modifications, may result in species-specific changes of contractile, metabolic and signaling protein patterns as shown by recent findings of muscle proteomics, from small rodents (mouse and rat) to humans. The present work is aimed at analyzing the results of muscle proteomics work carried out in human subjects: 1) In physiological and paraphysiological conditions (hypoxia, cold and overfeeding, exercise training, aging and immobilization). In this context, a special effort was made to extend the analysis to different muscles (soleus, gastrocnemius and deltoideus, within and between subjects) besides the vastus lateralis which has been, by far, the most investigated tissue for ultrastructural, biochemical and proteomics research; 2) In patients affected by various pathologic conditions such as neuromuscular hereditary disorders (NMDs) and type 2 diabetes. In addition, whenever possible, similarities or differences between results from human and animal proteomics studies have been outlined, with particular emphasis placed on the effects of hypoxia, exercise and training, immobilization and aging.

\section{Some aspects of the plasticity of human muscle fibers}

\subsection{Myosin heavy chain (MHC) isoforms and changes of MHC expression}

As is well known, myosin is the most abundant protein expressed in striated muscle fibrocells, i.e., $~ 25 \%$ of their total protein pool. The myosin molecule is a hexamere featuring two heavy chains (molecular mass of $22 \mathrm{kDa}$ each) whose carboxy-terminal portions form an $\alpha$-helical coiled-coil rod (the "tail") whereas the two separated amino-terminal portions form two elongated globular domains (the "heads"). Each "head" comprises the S1 subfragment of the heavy chain (the "neck") and contains a catalytic site for binding and hydrolyzing ATP as well as a site for binding actin in the thin filament: Each "neck" is associated with two non-identical pairs of myosin light chains, the "essential" ELC or "alkali" $25 \mathrm{kDa}, \mathrm{MLC} 1$ and the "regulatory" RLC or "phosphorylatable" $20 \mathrm{kDa}$, MLC 2 (Fig. 1). Both MHCs and MLCs exist in several isoforms in different fiber types and are the product of three multigene families, presumably derived from a single ancestor gene. The MHC family comprises several genes, each encoding a distinct isoform. Since the MHC gene family is sensitive to mechanical and hormonal stimuli, it will serve as a cellular "marker" for muscle plasticity and adaptive responses [4]. At least $10 \mathrm{MHC}$ isoforms produced by distinct genes have been identified in mammalian striated (heart and skeletal) muscles: 1) embryonic; 2) neonatal; 3) cardiac $\alpha$; 4) cardiac $\beta$ or slow type 1 , as expressed by the same gene, particularly in adult slow skeletal muscles; 5) fast $2 \mathrm{~A}$; 6) fast $2 \mathrm{X} / 2 \mathrm{D}$; 7) fast $2 \mathrm{~B}$; 8 ) extraocular; 9) mandibular or masticatory (m-MHC) and 10) the slow tonic MHC. In addition to type $1 \mathrm{MHC}$, adult skeletal 


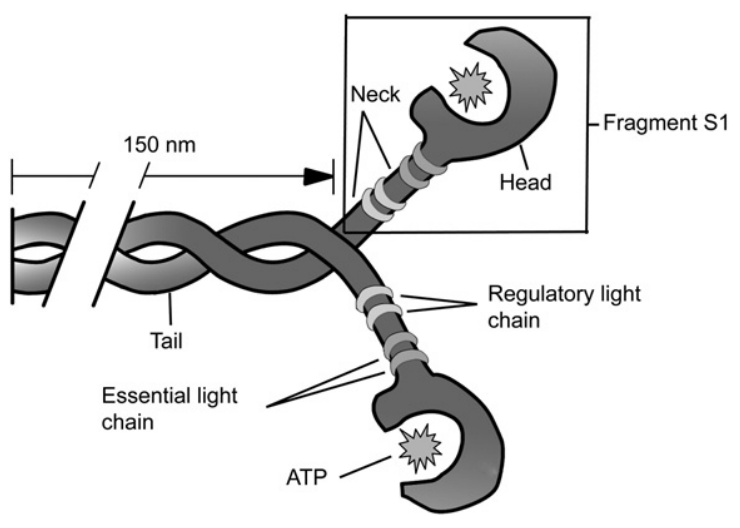

Fig. 1 - Schematic representation of the myosin molecule. Myosin is a hexamere featuring two heavy chains, each one characterized by three different regions: tail, neck and head. Moreover, each neck is associated to two non-identical pairs of myosin light chains (essential and regulatory, respectively).

muscles express in humans various proportions of fast-type $2 \mathrm{~A}$ and $2 \mathrm{X}$ MHC whereas type $2 \mathrm{~B}$ is not detected, at variance with its transcript [5]. In humans, the cardiac slow $\alpha$ and $\beta$ genes are located on chromosome 14, whereas the other genes, including the adult fast MHC 2A and 2X, are found on chromosome 17 in a relative tight cluster. Thick filaments in mammalian striated muscles are composed of $\sim 600$ myosin molecules whose "tails" point toward the center of the sarcomere (the myofiber functional unit) whereas the "heads" protrude from the filament every $60^{\circ}$ for binding with actin. Myosin, the motor protein, is a mechanical-chemical enzyme converting, via ATP-ase activity, chemical into mechanical energy and represents the molecular basis for force generation and contractile function. The contractile properties of striated muscles are imposed mainly by the pattern of myosin heavy chain isoforms expressed in the fibers. For almost half a century, skeletal muscle fibers appeared to cluster into similar groups of cells with each fiber being innervated by the same motor neuron (motor unit), the latter being characterized by the same histochemical staining for ATP-ase and by common biochemical and physiological properties. Over the last two decades, the composition of individual fibers was accurately assessed by means of immuno-histochemical techniques or, alternatively, of gel electrophoresis to separate the MHC isoforms. The results show that single fibers can express more than one MHC isoforms [6-9]. Thus, fibers from mammals were found to contain variable proportions of MHC hybrids coexpressing, at the protein level, up to four isoforms [10]. This makes up the spectrum of various motor units and sheds light on the plasticity of expression of the MHC gene family as well as on its regulation. Indeed, skeletal muscle fibers are elongated multinucleated cells containing a very large number of myonuclei, each controlling protein synthesis within its surrounding cytoplasm, constituting a series of myonuclear domains that, responding to localized signals, may result in differential gene expression along the fiber [11]. The fraction of hybrid fibers in the vastus lateralis muscle of normal young adults is $\sim 6 \%$ for both types $1+2 \mathrm{~A}$ and type $\mathrm{A}+2 \mathrm{X}$ and none of the fibers contains more than two $\mathrm{MHC}$ isoforms [12]. Differences between muscles and speciesspecific variants were also found [11].

\subsection{Myosin light chain polymorphism}

As indicated earlier, in each muscle myosin molecule, MLCs consist of a pair of essential light chains (MLC 1 and/or MLC 3) and of a pair of regulatory light chains (in skeletal muscle, MLC 2) that are non-covalently associated with the MHC at the base of the "neck" segment. All vertebrates express a specific subfamily of essential and regulatory isoforms in their skeletal muscles in combination with MHC isoforms. Skeletal muscle type 1 slow fibers express MHC 1 together with a slow isoform of essential MLC (MLC $1 \mathrm{~s}$ ) and of a regulatory MLC (MLC $2 \mathrm{~s}$ ) light chain, respectively; in fast fibers, MHC isoforms are associated with two distinct isoforms of essential (MLC 1f or MLC 3f, originating from a single gene) and one isoform of regulatory MLC $2 \mathrm{f}$ light chains. Each MLC is coded by distinct genes dispersed in different chromosomes. In a given species, changing associations of various MHC and MLC isoforms, generate populations of muscle fibers with a large range of specific functional properties. Stevens et al. have shown in the rat soleus that the MHC type 2 us type 1 ratio varied in parallel to the fast to slow ratio of regulatory and essential MLC isoforms [13]. In human skeletal muscles it has been established that MLC isoforms, in association with MHC, influence maximum shortening velocity [14]. MHC isoforms are the main determinant of myosin ATP-ase activity whereas the ELC isoforms play a significant regulatory role when ATPase activity is determined at low ionic strength [15].

Since muscle adaptation involves changes in myosin isoform composition and the latter controls contractile muscle function, it is expected that muscle adaptation will also change the contractile function. Particularly in transforming muscles, hybrid fibers could contribute to the functional plasticity of muscles by rapidly changing functional parameters such as $\mathrm{V}_{\max }$, the tension/ $\mathrm{pCa}^{2+}$ relationship and maximal force [11].

\subsection{Thin filament myofibrillar proteins}

As shown in Fig. 2, actin is a globular protein (G actin, molecular mass of $\sim 43 \mathrm{kDa}$ ) that polymerizes forming actin $\mathrm{F}$ filaments representing the backbone of the thin filament with a two-stranded long-pitch helical structure. $\mathrm{Ca}^{2+}$ regulates interactions between myosin and actin via tropomyosins (Tm) and the troponin (Tn) complex. Actin comprises $\sim 20 \%$ of

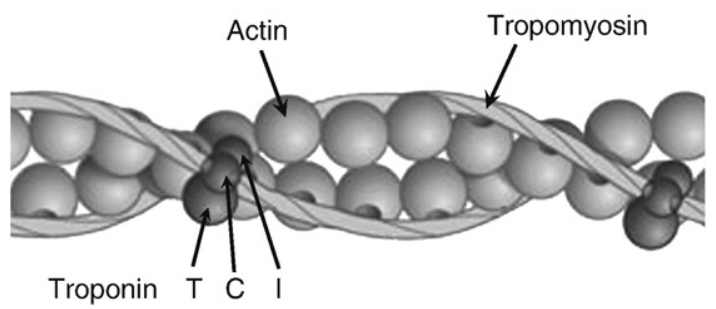

Fig. 2 - Thin filament structure. In the thin filaments of muscle, actin, tropomyosin, troponin I, troponin C, and troponin $\mathrm{T}$ are arranged regularly to form a protein complex. 
myofibrillar proteins and $12 \%$ of total proteins in skeletal muscle [16]. Each actin monomer comprises four subdomains: the smaller ones, 1 and 2, are located at the periphery of the filament (outside of the helix) interacting with myosin by means of $\mathrm{NH}_{2}$ and $\mathrm{COOH}$ termini; subdomains 3 and 4 are close to the helix axis and interact with homologous subdomains of other actin monomers. There are two sarcomeric actin isoforms, $\alpha$-skeletal and $\alpha$-cardiac actins, each variant being coded by a distinct gene, differing only by 4 substitutions highly conserved during vertebrate evolution. Functional features of actin depend on its level of expression and not on isoform changes. Loss of weight-bearing function causes skeletal muscle atrophy which, at the protein level, is characterized by a higher loss of actin thin filaments than myosin thick filaments [17]. This structural change of the sarcomere causes earlier cross-bridge detachment and faster cycling and may explain the increase of fiber 1 and 2A velocity of shortening after exposure to microgravity. Myofiber hypertrophy induced by heavy leg resistance-exercise does not affect human $\alpha$-skeletal actin expression [18].

\subsection{Muscle contractile protein-induced post-translational changes}

Post-translational modifications can induce altered modulation in the activity of proteins involved in muscle contraction as well as dysregulation of metabolic functions. Regulatory muscle light chains (MLC 2) feature sites suitable for phosphorylation thereby altering the control of myosin-actin interaction, e.g. by increasing $\mathrm{Ca}^{2+}$ sensitivity of the fiber. A clear correlation could be observed between increased MLC 2 phosphorylation and slow-to-fast phenotype transition [11]. The role of phosphorylation of $\alpha$ - and $\beta$-tropomyosins in adult humans remains under discussion as are the effects of posttranslational modifications of troponin. Regarding glycosylation of muscle proteins, the role of such post-translational change in the regulation of muscle function has not been considered yet [19].

\subsection{Signaling molecules in pathways controlling muscle fiber size and type}

Muscle hypertrophy and atrophy and the switching of fibers from fast to slow phenotypes and vice-versa are largely induced by the pattern of nerve activity and by the mechanical load imposed on the tissue and have, as outcome, changes of force generation, speed of shortening and resistance to fatigue. Among the factors mediating the effects of nerve stimulation are a series of intracellular signaling circuits and of transcription factors and co-factors controlling muscle gene expression, i.e. the players of the so-called excitation-transcription coupling [20] which likely involve a variety of pathways triggered by various steps along the excitation-contraction coupling and the complex pathways of post-contraction events. Among these, the reactions triggered by calcineurin and $\mathrm{Ca}^{2+} /$ calmodulin-dependent protein kinase (CaMK), the pathway triggered by muscle contraction (e.g. PKB/Akt) and those elicited by metabolic changes (e.g., AMPK) shown to affect muscle fiber size and type (Fig. 3). Genetic approaches to either, block or stimulate specific signaling pathways, and have been adopted in both in

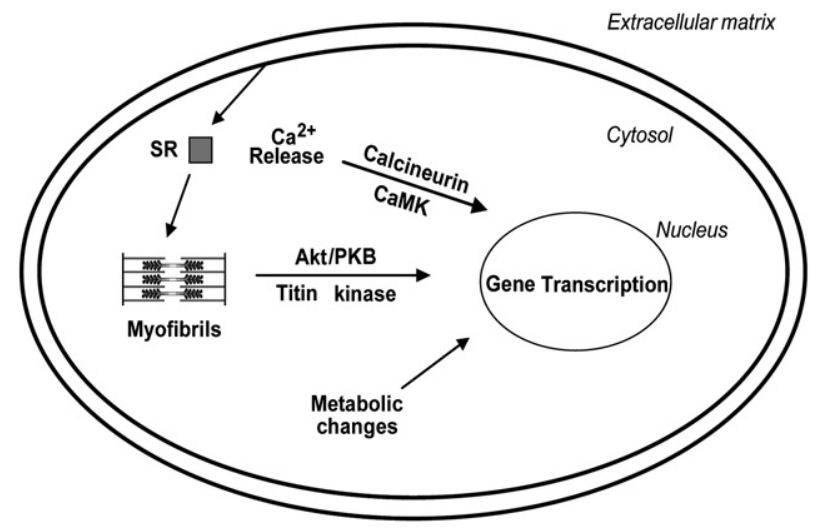

Fig. 3 - Excitation-transcription coupling. The figure shows a series of intracellular signaling circuits and of transcription factors and co-factors controlling muscle gene expression. Among these factors are the reactions triggered by calcineurin and $\mathrm{Ca}^{2+} /$ calmodulin-dependent protein kinase (CaMK), the pathway triggered by muscle contraction (PKB/Akt) and metabolic changes (AMPK).

vitro and in vivo experimental models. By means of in vivo models, the above authors were able to describe the function of the Ras-ERK and calcineurin-NFAT pathways in the induction and maintenance of the slow phenotype as well as the role of the Akt-mTOR and Akt-FOX-O pathways in muscle atrophy and hypertrophy [21]. More recently, several players of metabolic signaling pathways started being investigated by differential proteomics and could be correlated with upstream regulators of muscle function.

\section{The contribution of proteomics to the study of human muscle}

\subsection{The systematic definition of "muscle proteome"}

After up-dating basic notions of myofibrillar protein ultrastructure and of muscle plasticity and shortly outlining some of the signaling pathways known to control activity-dependent fiber responses, we shall describe the contributions made so far by proteomics in the study of skeletal muscle. Particular emphasis is laid on the identification of datasets of proteins potentially detectable in human muscle, thereby providing the background for the comprehension of unknown paraphysiological and physiopathological mechanisms affecting its function.

After the pioneering work of Giometti and Anderson [22-24] investigations on human muscle proteome, also including post translational modifications, were resumed with a study whereby $\sim 500$ protein spots of the vastus lateralis muscle from a pool of healthy Asian subjects were separated by twodimensional gel electrophoresis (2DE) [25]. Gels were silver stained adopting the protocol of Yan et al. [26] and spots manually excised. 124 spots were identified by MALDI-ToF MS and HPLC-ESI-MS/MS. Among these, several myofibrillar contractile proteins were found, including myosin lightchain 1 and 2 isoforms, actins, $\alpha$-chain tropomyosin, troponin 
I and three myoglobin isoforms, together with a large number of enzymes involved in glycolytic and aerobic metabolism. From this work, it appeared that the wide distribution of protein spots within 2D gels, due to the high dynamic range of muscle tissue, might affect the detection of the less abundant molecules, hence the need for additional, more specific separation steps in different $\mathrm{pH}$ ranges. Indeed, the distribution of contractile proteins in 2D maps was not homogeneous, with the most abundant spots being concentrated within the acidic range whereas a large number of regulatory proteins were located in the alkaline region of the gel (Fig. 4). Moreover, despite the high separative power of 2DE, a consistent number of contractile proteins characterized by high molecular weight (e.g. titin, nebulin, and MHC), hydrophobic molecules and proteins with very alkaline pI could not be separated. Conversely, the 2DE technology presented some advantages for muscle proteomic analysis, particularly for its capability of separating isoforms, i.e. crucial elements for the muscle functional assessment.

Before describing the most recent technical advances that follow the preliminary investigation in systematic muscle proteomics, two important issues must be raised, i.e. that of the high tissue composition variability (intra- and interindividual, within muscles and even fibers) and that of tissue plasticity, the latter expected to potentially influence the reproducibility of most experimental findings. Even though muscle protein characterization was initially carried out by two dimensional gel electrophoresis (2DE), due to its limitations to provide a global view of the muscle proteome, it was necessary to combine alternative technologies. In this context, different muscle characterizations were attempted by the use of shotgun proteomics [27], a technique developed for identifying proteins in complex mixtures using a combination of HPLC and mass spectrometry. In principle, this technology can overcome the limitations imposed by 2D electrophoresis. In fact, the latter is able to cope with the dynamic range of muscle proteome, but the sensitivity of hyphenated analytical techniques, combined with advancement in mass spectrometry resolution, remains incomparable, considering the possibility of using solubilizing agents that are compatible with the separative steps adopted prior to MS analysis. In earlier studies, the samples were digested by specific proteases (usually trypsin) and the peptides were separated and analyzed by mass spectrometry. The major disadvantage of this method is that nearly all protein isoformspecific information is lost [28]. In 2008, Hojlund et al. analyzed human vastus lateralis muscle by combining a fractionation by one-dimensional gel electrophoresis and subsequent HPLC-ESI MS/MS of lysates of 20-24 SDS gel slices digested with trypsin [29]. This approach allowed identification in 3 healthy subjects of a total of 954 different proteins comprising a large number of contractile molecules and most of the enzymes involved in the major pathways of glucose and lipid metabolism with a large share of mitochondrial enzymes. However, only 446 molecules were common to all investigated subjects introducing the issue

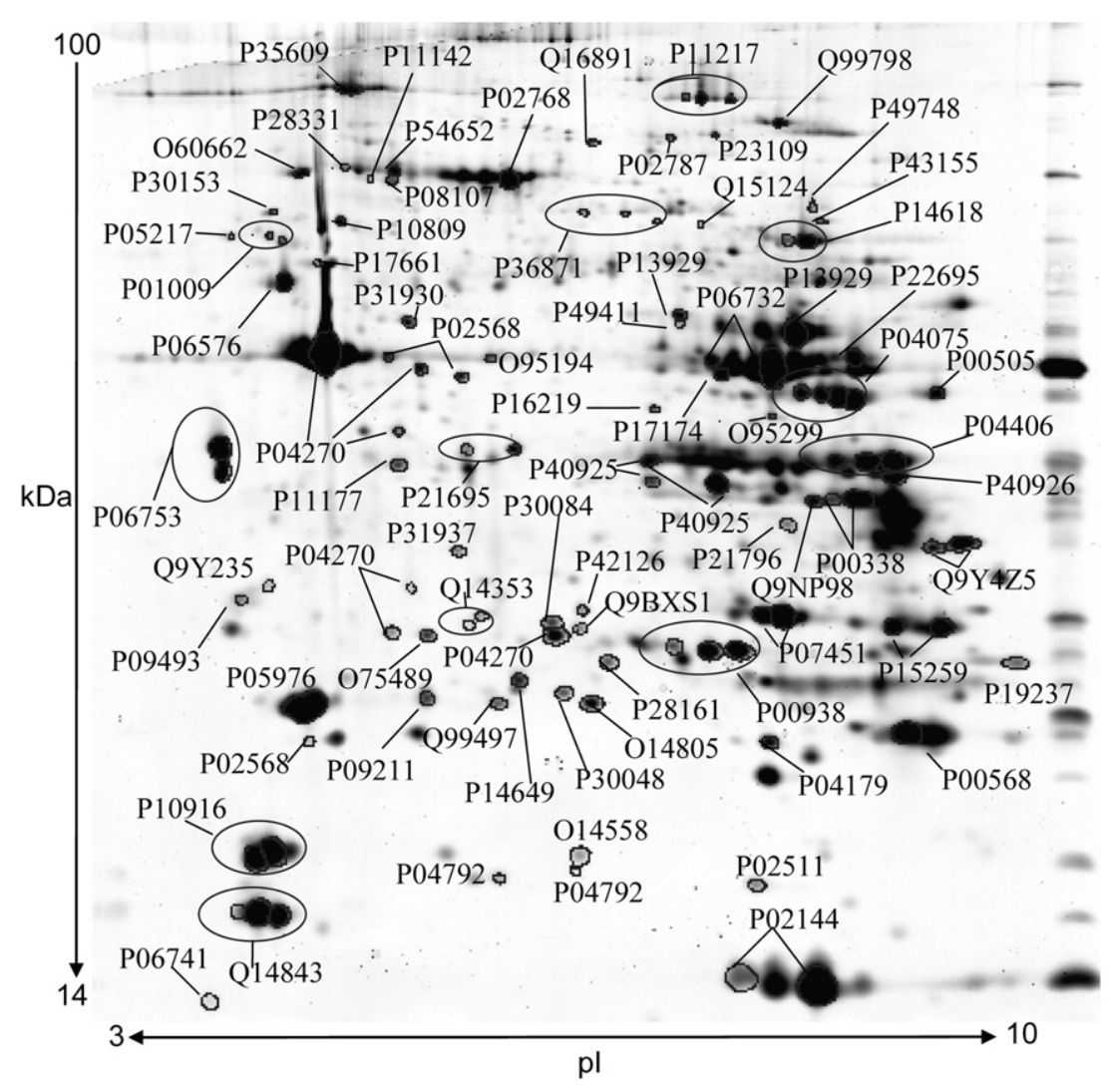

Fig. 4 - Vastus lateralis muscle 2-DE map. Proteins were separated using IPG pH 3-10 NL strip in the first dimension and SDS gel $(12 \% \mathrm{~T}, 2.5 \% \mathrm{C})$ in the second dimension and gel was silver stained. Proteins identified are indicated by circles and named with UniProt KB entries. 
of the large inter-individual variability outlined above. The reproducibility rate of two replicates made on the same sample for one of the subjects was found to be $75 \%$. As expected, the three major isoforms of MHC accounted for $42 \%$ of the total spectra. Therefore, the analytical volume taken by this abundant protein, presumably hampers the identification of less abundant proteins that co-migrate in the same gel region. By adopting sample pre-fractionation in a linear gradient of acrylamide (4-20\% T), the proportion of spectra accounting for MHC isoforms dropped to $32 \%$. Apart from the inter-individual variability, this study also highlighted the presence of isoforms of the same proteins which are crucial muscle functional regulators. The majority of proteins presented a single IPI Id but 230 of them were characterized by two associated Ids and 162 had more than two. Of the identified proteins (776 out of 954), $59 \%$ could be assigned to the cytoplasm, $22 \%$ to the mitochondria, whereas $17 \%$ were nuclear proteins. Broad proteomics coverage was shown of the major enzymes involved, e.g., in the phosphocreatine/creatine pool, i.e., the major source of energy phosphate bonds for ATP resynthesis in response to muscle contraction; in $\mathrm{Ca}^{2+}$ homeostasis, including three members of the voltage-dependent $\mathrm{Ca}^{2+}$-channel complex, ryanodine receptor 1, calmodulin, and several $\mathrm{Ca}^{2+}$-binding or regulated proteins such as calcineurin A and protein Kinase II; in glycogen metabolism; in the glycolytic pathway; in the citric acid cycle; in fatty acid transport and oxidation, as well as in oxidative phosphorylation. This methodological approach allowed definition of proteins that were out of the 2DE resolution range by also classifying 114 proteins of over $100 \mathrm{kDa}$ and 11 with MW of less than $10 \mathrm{kDa}$. Interestingly, proteins were grouped into the major pathways known to regulate muscle function such as glucose and lipid metabolism, electron transport and oxidative phosphorylation, calcium homeostasis, myofibrillar apparatus and components of IGF and insulin signaling, providing a comprehensive functional picture of the muscle proteome. Fig. 5 features the contractile proteins identified by this approach into a representative scheme of the sarcomere. Thus it would appear that the majority of contractile proteins can be identified by combining different proteomic methodologies thereby suggesting the possibility of optimizing proteome definition. The same authors [30] conducted a parallel study of gene expression profiles and proteome analysis on healthy individuals by combining the Affymetrix platform with the proteomic pipeline described above. Among the 5193 identified transcripts, 437 had their corresponding protein detected by mass spectrometry. Unfortunately, the gene expression profile was obtained from subjects that were different from those participating in the proteomic study. This could be one of the causes of the reduced overlap between gene products and proteins. However, even when both proteome and transcriptome were obtained from the same subject, only a slightly increased homology was observed raising a number of issues related to the significance and the interpretation of the results of these comparative studies. Apart from the use of different subjects and from the intrinsic variability of muscle tissue, unlike sensitivity and the different principles at the basis of the two technologies (unbiased us biased analyses), have to be taken into account. The advantage of combining these powerful technologies is not only to verify the existence of overlapping results, but to complement gene expression profile with

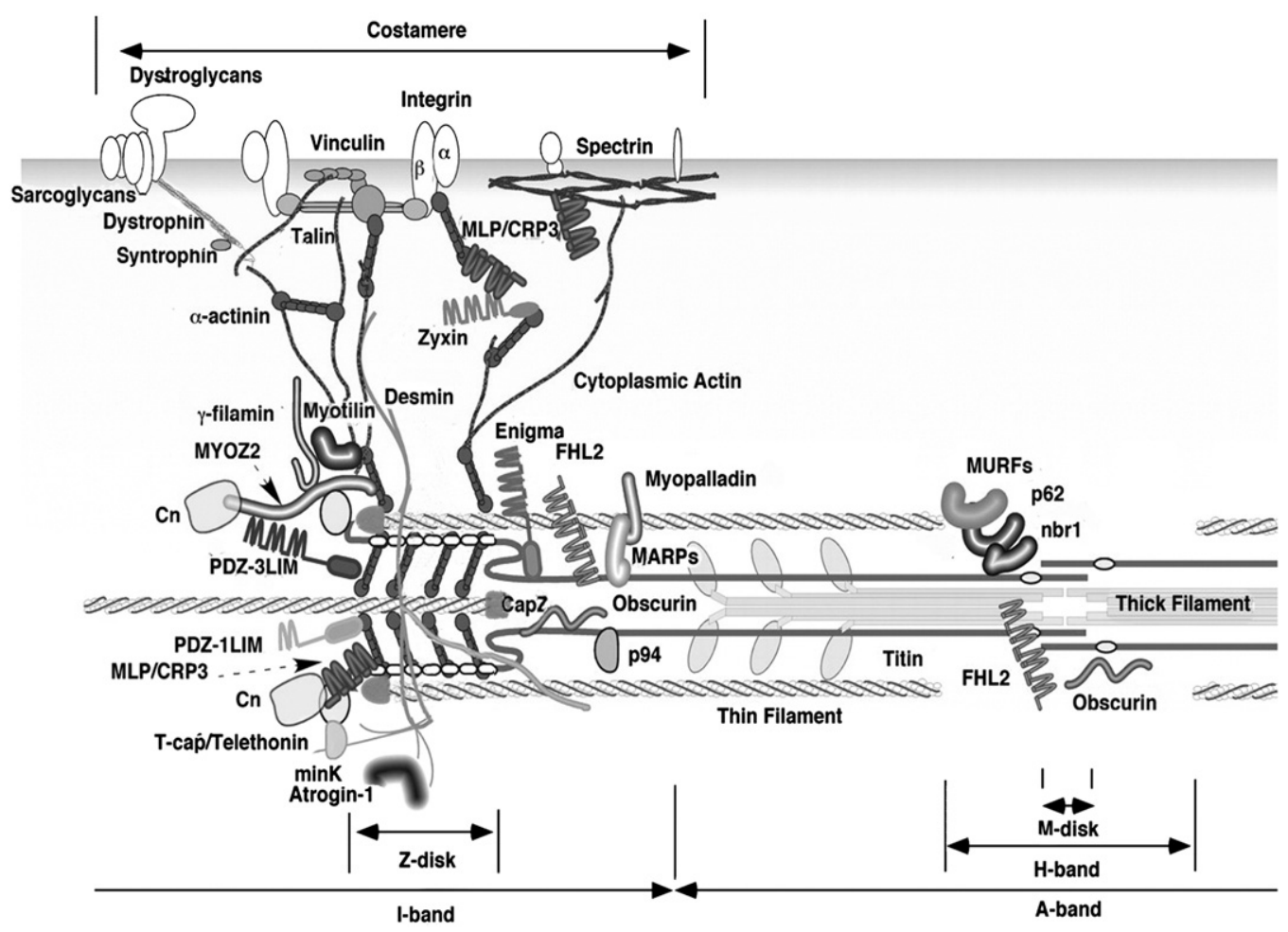

Fig. 5 - Structure of sarcomere. Proteins identified by Hojlund et al., combining one dimensional gel electrophoresis and HPLC-ESI-MS/MS, are indicated into a representative scheme of the sarcomere. 
proteomic data. It is also noteworthy that, when combined analyses of gene transcripts and proteins are planned, experiments should be performed on the same samples in order to increase the information provided by the two separated "omic" analyses. This joint approach generates an overall picture of the muscle thereby opening new avenues for evaluating the significance of muscle diversity in physiological and pathological conditions [31].

Recently, using four different workflows (1D and 2D peptide separation, SDS gels and differential solubilization), 2000 proteins were identified from samples of unspecified muscles obtained from 31 patients affected by a wide range of muscle diseases, particularly inflammatory myopathies, and from other patients that did not have muscle disorders [32]. A large number of proteins involved in muscle function were identified whereas differences between various muscles and/or subjects were not taken into account. The authors by using shotgun proteomics propose a list of candidates for the major structural components of the sarcomere. In this paper, two distinct technologies were compared, i.e., SDS gel-based protein fractionation followed by peptide digestion and $2 \mathrm{D}$ peptide separation. It would appear that the former is more efficient in terms of identification of proteins than the latter. In fact, sarcomeric proteins are lost when adopting 2D peptide separation in which the dynamic range of the sample is greater than allowed by the performances of the mass spectrometer. Conversely, in digested SDS samples, the most abundant proteins were confined to 2 or 3 slices, thereby increasing the detectability of the less abundant species. What should be pointed out is that the plasticity of muscle tissue is not taken into account as was the reproducibility of the data between various subjects or patients. In fact, proteins are considered when found in 2 out of 3 individuals.

\subsection{Post-translational modifications}

These changes represent an important issue to be faced in systematic and functional proteomic studies. Among others, phosphorylation represents a key regulatory mechanism controlling the activity of enzymes playing a crucial role in signal transduction pathways regulating energy metabolism, excitation-contraction coupling, sarcomeric function, muscle mass balance and fiber type distribution in relation to mechanical stress, inflammatory factors and hormones [33-35]. A number of hypothesis-driven studies have been conducted by analyzing phosphorylation of specific proteins along signaling pathways for which antibodies recognizing the phospho-epitope were available. To fill this gap, a phosphoproteome assessment after phosphopeptide enrichment by SCX and $\mathrm{TiO}_{2}$ by HPLC-ESI MS/MS from 3 to $5 \mathrm{mg}$ of muscle protein extracts of $30-50 \mathrm{mg}$ of tissue samples obtained by surgical biopsies from the vastus lateralis muscle of 3 lean, healthy volunteers was performed [36]. In total the authors could identify 367 phosphorylation sites (phosphotyrosine, phosphoserine, phosphothreonine) in 144 proteins from at least 2 out of 3 subjects. As a result, after phosphopeptide enrichment, $\sim 35 \%$ of the identified proteins were phosphoproteins. Fig. 6 shows the number of phosphorylation sites localized in the various muscle functional compartments. These results provide possible targets of phosphorylation

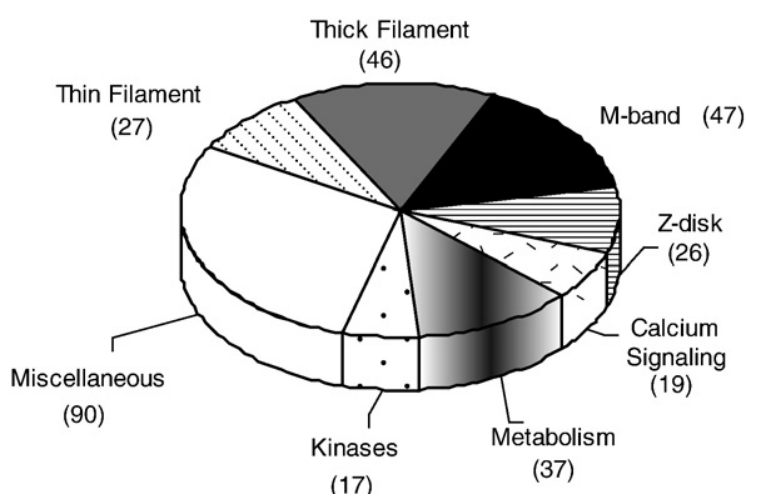

(17)

(37)

Fig. 6 - Phosphorylation distribution. Pie chart shows the number of phosphorylation sites localized in various muscle functional compartments and pathways.

signaling for the investigation of human skeletal muscle in health and disease. In any case, further studies are needed to fully understand the functional significance of these sites.

\subsection{The proteomic profile of functional mitochondria}

Special emphasis shall also be placed on the study of human skeletal muscle mitochondria for the possible assessment of proteins from small samples of healthy and diseased skeletal muscles $[37,38]$. In the above investigation, $100 \mathrm{mg}$ of tissue biopsies were utilized for mitochondrial enrichment. With this amount of tissue, the authors could perform both functional and proteome characterizations of muscle mitochondria. The mitochondrial enriched fractions from healthy individuals were separated by 1D SDS and HPLC ESI MS/MS as previously described for skeletal muscle. As mentioned before, a combination of methodologies appeared to be the appropriate choice for systematic studies on a restricted number of subjects, since it provided an exhaustive list of proteins expressed in a specific cellular compartment. In this case, results obtained from 4 healthy subjects provided different datasets and, by comparison and elimination of redundancies, 823 unique proteins could be identified of which 487 were assigned to the mitochondria. This dataset is representative of a muscle extract enriched in mitochondria in which muscle proteins are also present and represent the most exhaustive list of mitochondrial muscle proteins so far (Fig. 7). Recently, Zhao et al., combining different phosphopeptide enrichment approaches with high performance LC-MS/MS, presented the phosphorylation pattern of isolated mitochondria from muscle of five healthy volunteers [38]. The authors identified 155 distinct phosphorylation sites in 77 mitochondrial phosphoproteins.

\section{Differential studies under physiological and paraphysiological conditions}

A large section of the review shall be devoted to muscle comparative proteomics with the aim of providing a global view of the protein spectrum expressed in functionally different muscles, in control conditions and at rest. The protein pattern of a variety of homologous muscles from a large number of 


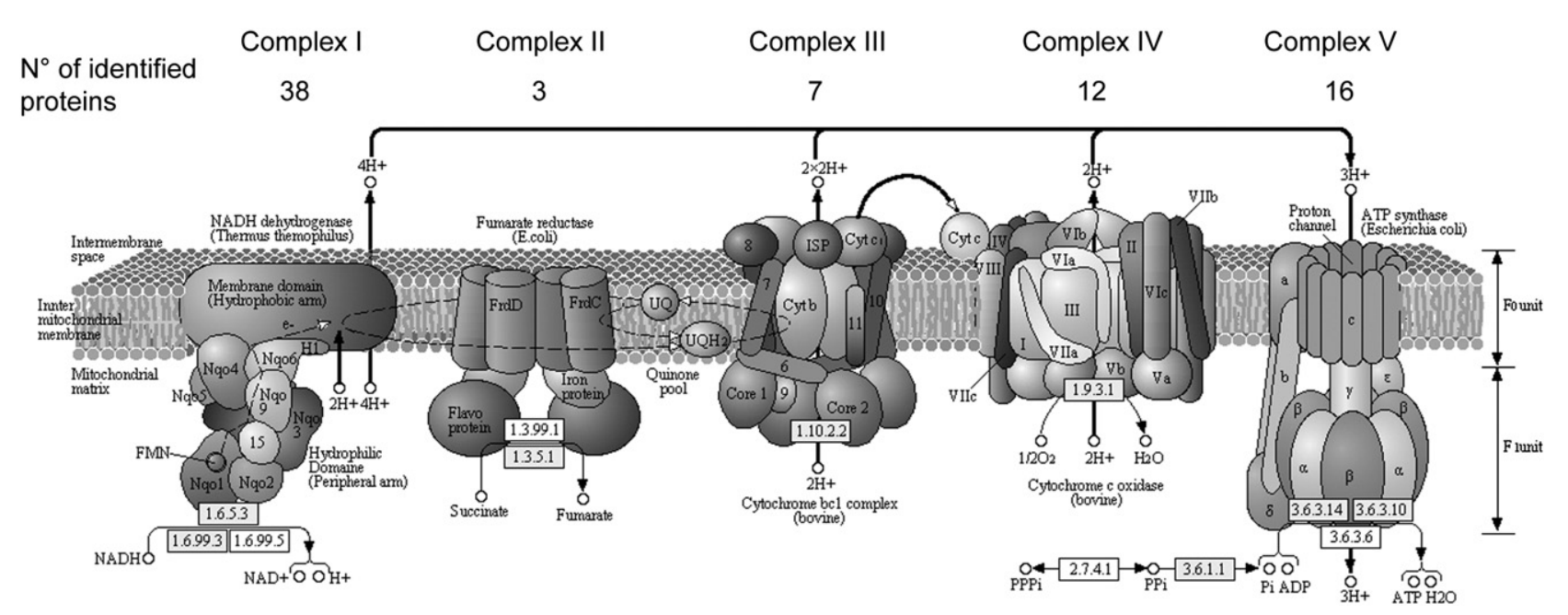

Fig. 7 - Oxidative phosphorylation pathway. Number of proteins identified by Lefort et al. in each complex is indicated in a representative scheme of oxidative phosphorylation pathway. (Modified from KEGG).

healthy individuals, that is a pre-requisite for investigating differential response to a set of age- and gender-dependent, nutritional, exercise and environmental conditions, shall be also presented and discussed. In addition, proteomic data from pertinent animal models shall be outlined. The latter, despite the diversity in muscle structures, fiber type distribution and metabolism, may represent useful tools for human studies, particularly for the comprehension of specific molecular mechanisms at the basis of adaptation to particular experimental conditions and/or to disease. Until recently, the muscle proteome was mainly assessed combining protein separation by two-dimensional gel electrophoresis (2DE), adopting the silver stain protocol and 2D-DIGE according to Unlu et al. [39] and Tonge et al. [40], followed by protein identification by MALDI-ToF MS and/or HPLC-ESI-MS/MS analysis $[25,41-45]$.

4.1. The proteome of muscle tissue under chronic and subacute hypoxia

\subsubsection{Chronic hypoxia}

Based on the knowledge of their excellent exercise performance at high altitude, the first study applying the proteomic approach to a physiological investigation was aimed at analyzing the differences in the vastus lateralis enzymatic protein pattern between 9 high altitude Tibetan natives (Tib1) shortly after a descent to moderate altitude, 6 secondgeneration Tibetans (Tib2) born and living in Kathmandu (1300 $\mathrm{m}$ a.s.l.) and never exposed to altitude before, and a group of Nepali control subjects $(\mathrm{N})$ native to moderate altitude [42]. Investigated subjects were homogeneous for age and gender. Muscle bioptic material was analyzed adopting 2DE and ESI MS/MS for protein identification. The aim was to correlate muscle functional features with possible changes in the proteome. A restricted set of metabolic and regulatory molecules ( $n=7$, identified as: glutathione-S-transferase, $\Delta^{2}$-enoyl-CoA-hydratase, phosphoglycerate mutase,
NADH-ubiquinone oxidoreductase and myoglobin, all increased; lactate dehydrogenase, glyceraldehyde-3-phosphate dehydrogenase, both decreased) was found to be changed by a stringent statistical analysis. Some of the protein changes found in altitude Sherpas were also present in Tib2. The increased abundance of myoglobin isoforms observed in Tib1 sheds light on the possible alternative role of myoglobin as a signaling molecule beside that of a classical oxygen store. It should also be pointed out that the most abundant contractile proteins were absent from this differential profile obtained by comparing 500 spots, underlining the concept that an adequate number of subjects, their homogeneity, together with that of the sampling procedures, are essential features for detecting actual alterations. A correlation of protein changes with those of upstream markers of hypoxia assessed by mRNA quantitation in Tib1, i.e., an increased expression of HIF, eNOS and nNOS, was also found. In conclusion, muscle proteomic analysis has highlighted some mechanisms by which high altitude populations adapt to hypoxia, prevent tissue damage from ROS, and optimize metabolic control, thereby improving physical activity under extreme conditions. The results of this study support the relevance of differential proteomics for the analysis of muscle function.

\subsubsection{Subacute hypoxia}

The introduction of the 2D-DIGE technology [39,40] allowed a step forward in muscle protein research, particularly in physiological studies for which only a restricted number of bioptic samples are usually available. In fact, the presence of an internal standard with the co-migration of samples, automated spot detection, powerful statistical analysis and, last but not least, the high sensitivity of the method, allows better detection of the changes in the protein pattern. The method was applied successfully to the study of hypoxia adaptation in healthy subjects. Muscle adaptative changes occurring in the early phase of hypoxia exposure were assessed in the vastus lateralis muscle of 10 young, physically 
active Caucasians, before and after a 7-9 day-exposure to high altitude during acclimatization to hypobaric hypoxia (Margherita Hut, Monte Rosa, 4559 m.) [46]. The results indicate that proteins involved in iron transport, TCA cycle, oxidative phosphorylation and oxidative stress response, assessed in hypoxia at the end of altitude exposure, were significantly decreased. In this study, hypoxia markers such as the hypoxia inducible factor (HIF-1 $\alpha$ ) and pyruvate dehydrogenase kinase (PDK1), after 7 to 9 days of exposure, were at the pre-hypoxia levels, indicating that the early adaptive response to hypoxia of human muscle does not involve the stabilization of HIF- $1 \alpha$. Accordingly, the mammalian target of rapamycin (mTOR) was also reduced, indicating that adaptation to hypoxia also imposes a continuous control of muscle energy balance as supported by the observed decrement of the translation initiation factor $2 \alpha$ (eIF $2 \alpha$ ) involved in the control of protein synthesis.

Animal models have been also adopted for muscle research in hypoxia. Investigations on rat gastrocnemius muscle have indicated [47] that a two week exposure to $10 \%$ oxygen breathing, activates the HIF-1 $\alpha$ gene program which includes a decrement of TCA cycle and oxidative metabolism, and an increment of glycolytic enzymes and deaminases involved in ATP and AMP production. This coordinated metabolic response is the result of an increment of PDK1 that shuttles the pyruvate away from the generation of acetyl-CoA thereby enhancing conversion to lactate (anaerobic glycolysis). Thus, hypoxia adaptation differs from that of humans as outlined above. However, it should be pointed out that the experimental protocols adopted for the human and animal experiments referred to, cannot be compared, based on the species-specific metabolic characteristics of the models. Indeed, the experimental conditions in the rat could be considered similar to that of a subchronic exposure for men, taking into account the relatively greater fraction of life span affected by hypoxia. Further investigations will be required to profile the proteome modulation in rodents and other models (e.g. zebrafish) [48] based on different exposure times and hypoxia levels in order to make it possible the transfer of results to humans. These findings could be of particular interest for the selection of specific molecular targets for prognosis or for pharmacological interventions in diseases like COPD in which muscle adaptation to hypoxia can facilitate a positive outcome [49]. The described results underline the potential of differential proteomics in providing new insight into the mechanisms of adaptation to reduced $\mathrm{O}_{2}$ pressure in conditions in which hypoxia is not the consequence of a disease. In the latter, in fact, it will be difficult to discriminate disease-induced changes from those by hypoxia "per se".

\subsection{Differential proteomics of muscles from the same subject: Vastus lateralis us deltoideus}

The different individual protein expressions in human deltoideus and vastus lateralis muscle of healthy sedentary subjects were investigated by 2DE and ESI MS/MS [41]. These muscles are characterized by similar ATP-ase-based fiber type distribution [50] but differ ultrastructurally and metabolically [51]. Both have been extensively utilized for studies of muscle plasticity. In the above investigation, low molecular weight contractile protein isoforms compatible with the separative range of 2D gels, were analyzed differentially, both qualitatively and quantitatively, by utilizing narrow $\mathrm{pH}$ gradients: $\mathrm{pH}$ 4-5 for troponin isoform assessment and pH 4.5-5.5 for MLC isoforms. Several isoforms typical of fast and slow fibers were detected and their quantitative expression was found to be correlated with MHC isoform distribution, i.e., indirectly, with fiber type distribution. However, the assessment of the MHC, MLC and of the troponin pool of isoforms in muscle extracts does not reveal anything about hybrid fibers which, as stated in the Introduction of the review, may be present in most muscles. Hybrid fibers are known to express isoforms that are typical of fast and slow fibers even in different regions of the same fiber [8,52]. Therefore, data obtained on muscle extracts are informative only of the composition of the pool of fibers present in a homogenized sample. The distribution of both MLC and troponin was consistent with that of MHC (Fig. 8). Apart from the characteristics of isoform distribution of some contractile proteins, what appears relevant in this study is the variety of metabolic proteins involved in glycolysis, TCA cycle, oxidative phosphorylation and respiratory chain complexes. These are more abundant in the vastus lateralis than in the deltoideus, in line with the higher oxidative capacity of the former. This finding is consistent with the functional role of the vastus lateralis that is a locomotor and antigravity muscle in constant use, whereas the deltoideus is unloaded for most of the time. Also of note were the differences in isoforms of some stress proteins, particularly peroxiredoxin and Hspb6.

For a more precise assessment of muscle plasticity and to gain insight into the different responses to physiological, paraphysiological and pathological stimuli of different muscles, it would be essential to catalog proteins expressed in isolated fast and/or slow fibers. As already highlighted in the systematic section of this review, proteomics, particularly when based on protein separation on $2 \mathrm{D}$ gels, fails to provide the largest catalog of proteins expressed in a single fast or slow fiber, due to the scarcity of material (few $\mu \mathrm{g}$ 's of proteins distributed in a large dynamic range). The analysis of whole muscles with different fiber type compositions, such as the soleus, that is prevalently oxidative, and the gastrocnemius that is characterized by a fiber mixed composition, allows to partially bypass this issue. Indeed, proteome analysis of these two muscles in the rat provided two sets of proteins

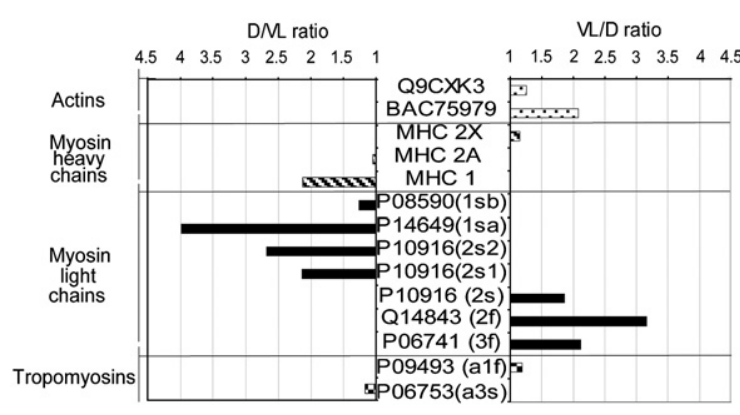

Fig. 8 - Quantitative distribution of contractile proteins. Histogram shows the distribution of actins, MHC, MLC and tropomyosins in vastus lateralis and deltoideus muscles. Modified from Capitanio et al. [34]. 
comprising different functional categories [53]. Apart from the quantitative assessment of the different isoform distributions of some contractile proteins in the two investigated muscles, a greatly different abundance of molecules controlling glycolysis was found. The latter were 4-15 folds more elevated in the gastrocnemius than in a soleus which, in turn, was characterized by substantially higher levels of carbonic anhydrase 3 and myoglobin. The same was true for the level of several other proteins such as PDZ-LiM domain protein and glyoxylase (more abundant in gastrocnemius) and annexin A6, regulating $\mathrm{Ca}^{2+}$ release from intracellular compartment, and HSP20 that were more abundant in soleus. Thus, the muscle proteome of animal models may provide important hints to muscle plasticity comprehension. In particular, it helps to clarify why some muscles are more influenced than others by changing physiological and or experimental conditions such as aging, hypoxia, microgravity, lack of exercise, or by secondary effects induced by the primary defect, as in some neuromuscular disorders.

\subsection{Metabolic response to cold and overfeeding}

In addition to being responsible for force generation and locomotion, muscle is a large mass comprising $40 \%$ of the human body and a tissue characterized by a wide metabolic spectrum. Upon mild cold exposure, sympathomimetic druginduced thermogenesis $[54,55]$ leads to profound changes in muscle mass, composition and metabolism by way of muscle mitochondrial uncoupling and the consequent increase in energy expenditure [56]. The effects of thermogenesis were investigated in 9 healthy lean subjects by Wijers et al. [57] with the aim to identify the molecular mechanisms involved and the individual variability of various metabolic adaptations. Inter-individual differences of the latter might explain changes of weight due to small differences in energy expenditure which can lead to long term weight gain or loss [58]. The identification of metabolic proteins involved in the control of the electron transport chain upon overfeeding, as a control condition, us overfeeding combined with mild cold exposure, provided new tools to monitor weight gain. In the above study, the metabolic responses to cold and overfeeding of humans $(n=9)$ were determined in a respiration chamber in baseline conditions during three days of cold exposure and compared with three days of overfeeding. After each experiment a biopsy was taken from the vastus lateralis muscle and extracted proteins were analyzed by $2 \mathrm{D}$ electrophoresis and MALDI-ToF MS. Three samples reflecting 3 different conditions (i.e. control, cold exposure and overfeeding), from the same subject, were run in a 2D gel and fluorescently stained. Among the 95 differentially expressed proteins, 52 were identified. The analysis of 46 of them showed a positive correlation (by the non parametric Wilcoxon test) between changes in spot density and changes in energy expenditure by the subjects. The majority of protein changes upon cold exposure or overfeeding affected enzymes of the glycolytic pathway. Unfortunately, validation of differential analysis by 2D immunoblots, was not possible due to lack of material, and 1D immunoblots of key glycolytic enzymes did not confirm the differential proteomic results. Following overfeeding and cold exposure, the abundance of these proteins increased slightly, but the found small differences were related to interindividual variability to thermogenesis adaptation. Moreover, increased abundance in ATP synthase subunits suggested an increased ATP production. The authors concluded that the expectation of a correlation between detected protein changes and both cold- and overfeeding-induced adaptive thermogenesis was not supported by the experimental results. It has been pointed out that the found interindividual differences in adaptive thermogenesis might originate from differences in enzyme activity rather than from changes in protein concentration, suggesting that a different approach, possibly directed to the assessment of membrane proteins, could be more reliable to detect proteins responsible for the mitochondrial uncoupling. Calcium cycling and protein turnover, i.e. mechanisms possibly responsible for downstream ATP-consumption should be taken into consideration as well as the energy status of other tissues such as brown fat and liver. These conclusions also address the general issue of the limited number of proteins that can be visualized in a $2 \mathrm{D}$ gel and of the possible discrepancy between protein abundance and protein activity as well as of the difficulty in choosing the most appropriate methodological approach to investigate a complex problem such as the one proposed by the authors for which the use of an internal standard would have been mandatory.

\subsection{Exercise and exercise training}

Proteomic studies on adaptive changes of human muscles as a consequence of acute and chronic exercise are missing with the exception of a recent work by Holloway et al. on intervalexercise training [59]. Therefore, even though not strictly related to the aim of this review, at the bottom of this paragraph, we shall summarize the most significant muscle proteomic results on exercise and training obtained in some animal models, particularly the rat. The investigation on interval-exercise training indicated above was carried out on 5 recreationally active men who underwent a 6 week interval training protocol on a treadmill [59]. Thirty minute training sessions were repeated three times a week. Each session comprised six 1-min runs at $90-100 \%$ of maximum oxygen uptake ( $\left.\mathrm{V}_{\mathrm{O} 2} \mathrm{max}\right)$, interspersed by $4 \mathrm{~min}$ exercise bouts at $50 \%$ of $\mathrm{V}_{\mathrm{O} 2} \mathrm{max}$. Proteomic analyses were carried out on bioptic samples from the vastus lateralis muscle taken before the first, and $72 \mathrm{~h}$ after the last training session by 2DE and 1D SDS, followed by iTRAQ labeling and LC MS/MS. Interestingly, 2DE resolved 256 spots whereof only 20 were significantly changed. Proteins that were more abundant after intervaltraining included metabolic enzymes, myofibrillar, Hsp's and transport proteins. To implement proteomic data provided by 2DE, the authors introduced 1D SDS combined with iTRAQ labeling to facilitate quantitative expression analysis of baseline and post-exercise samples. Interval training significantly increased the expression of $\alpha$ - and $\beta$-chain subunits of ATP synthase that correlated positively with the changes of the encoded $\mathrm{Ca}^{2+}$-calmodulin-dependent kinase II activity. By 1D SDS-LC MS/MS platform, an increment of succinate dehydrogenase flavoprotein and of the $\alpha$-subunit of the mitochondrial trifunctional protein was found, which is consistent with previous findings by immunoblots after sprint 
interval training using cycle ergometry [60]. In fact, this protein catalyzes the last steps in $\beta$-oxidation of fatty acids. The $\alpha$-subunit is associated with 3-hydroxyacyl-CoA dehydrogenase and enoyl-CoA hydratase activities and an increased expression of this enzyme suggests a greater capacity to oxidize fatty acids. The importance of combining two separation technologies was that the information extracted by ITRAQ alone does not take into account isoform distribution, whereas 2DE provides a precise quantitation of the latter. These findings show that a combination of the two adopted technologies is required to unravel certain aspects of muscle complexity, particularly in comparative studies. Among contractile proteins, troponin $\mathrm{T}$ was extensively described in this paper and specific phosphorylated isoforms were found to be differentially changed after interval training.

Most of the proteomic investigations on animals were carried out in rats. The adopted exercise models were voluntary wheel running, swimming as well as intensitycontrolled treadmill running [61]. Skeletal muscle responses were investigated at rest, after acute exercise or prolonged training. Takahashi et al. [62] carried out 2DE on pooled muscles from rats killed after 150 min of swimming, reporting reduction of a putative transcriptional factor later identified as zinc finger protein 3. Guelfi et al. investigated the rat gastrocnemius $30 \mathrm{~min}$ after a $3 \mathrm{~min}$ swimming load [63]. Changes of troponin $\mathrm{T}$, creatine kinase, adenylate kinase and Hsp 20 were detected. Gandra et al. report significant changes in glycolytic enzymes, Hsp70 and carnitine palmitoyl transferase, in the recovery phase ( 3 and $24 \mathrm{~h}$ ) after a treadmill effort to exhaustion [64]. With reference to chronic exercise, Burniston found significant changes in the expression of 15 gel spots, corresponding to 11 individual genes, 6 of which are characterized by different alternative splicing gene products [61]. Endurance training altered the expression of a single protein isoform of transferrin, albumin, lactate dehydrogenase A (LDH A), phosphoglucomutase 1 (PGM1), triosephosphate isomerase and mitochondrial aconitase (ACON 2). The significance of changes in isoform distribution of these enzymes has not yet been clarified. As far as PGM1 is concerned, according to the authors, the general decrease in abundance of this protein could correspond to a significant decrease in its enzyme activity, whence the lesser ability to utilize glycogen with corresponding saving of the muscle stores of the latter and a greater use of fatty acids. Therefore, validation of the postulated mechanism will be useful. Yamaguchi et al. [65] have recently investigated by 2D-DIGE the changes induced by 5 days of high intensity swimming interval-training on the proteome of the rat epitrochlearis muscle. 13 proteins, mainly mitochondrial enzymes, exhibited changed expression compared to sedentary controls. An alternative experimental model for obtaining a comprehensive proteomic profiling of muscle transformation during exercise, is that of chronic low-frequency stimulation. Donoghue et al. analyzed by 2D-DIGE the protein differential expression response of the rabbit tibialis anterior (a fast twitch muscle) of 14 and 60 day conditioned animals us unstimulated controls [66].This comprised 41 protein species belonging to various known functional classes whose conversion, confirmed by immunoblotting, was toward slower twitch characteristics. As far as exercise is concerned, a transfer of proteomic differential data from animal models to human muscles is, at present, unwarranted.

\subsection{Aging}

Aging is characterized by a loss of muscle mass (sarcopenia), which in moderately-active, 75 year-old male subjects, may account for $\sim 25 \%$ of the lower limb muscle mass with concomitant reduction in maximal cross sectional anatomical and physiological areas, fascicle length, fiber pennation angle, maximum voluntary force and relaxation rate [67-69]. Functional changes at the fiber level include a loss of specific force both in vivo and in vitro $[12,70,71]$. Reported changes in fiber type distribution are contradictory, having featured either a shift toward a slower muscle phenotype following preferential denervation of fast motor units [72], no change at all [73,74] or even a shift toward a faster phenotype [12,75]. Age associated molecular changes include reduction in myosin heavy chain (MHC) [12,76], though the distribution of myosin light chains (MLC) remains unchanged, reduced protein synthesis [77], accumulation of lipofuscin [78], impairment of excitationcontraction coupling [79] and decline in respiratory chain function [80]. Given the complex nature of the aging process, considerable inter-individual and inter-group variabilities in age-related sarcopenia are not surprising. Since the amount of tissue obtainable at biopsy is necessarily limited, a joint assessment of all relevant parameters may not be possible. Age-dependent changes in contractile and metabolic proteins of the vastus lateralis muscle in two groups of physically active elderly and young subjects were assessed by 2D-DIGE with the aim of reducing the confounding effects of inter subject and group variations of both sarcomeric and metabolic proteins [43]. Vastus lateralis muscle samples of 6 subjects aged 70-76 years were compared to those of 6 individuals aged 2025 years. What appears of relevance is the drastic change, in the elderly, in metabolic proteins with a decrement of creatine kinase and of most enzymes involved in aerobic metabolism paralleled by an increment of those regulating anaerobic glycolysis. Myoglobin, sarcosin and peroxiredoxin 2 were also less abundant in the elderly, whereas glutamic oxalacetic transaminase 1 (GOT-1) was increased. Major differences were observed at the contractile level with decrements of MHC fragments, of the tropomyosin $\mathrm{R}$ chain and of troponin $\mathrm{T}$ levels. Differences were also observed in myosin light chain isoform distribution with changing abundance of slow and fast isoforms. Concentrations of fast isoforms of myosin regulatory light chains (MLC) and, in particular, of the regulatory phosphorylatable isoforms known to modulate the rate of force development and of twitch maximal force at different initial tension levels [81-83], both of which are relevant to muscle function, were decreased. In vitro phosphorylation of MLC is known to increase calcium sensitivity thereby controlling the rate of force development and maximal force [84]. The drop of phosphorylatable isoforms and the decrement of phosphorylation of the acidic MLC $f$ isoform found in elderly subjects, could impair performance. As is well known, aging induces a progressive reduction of the knee extensor muscle mass and maximal force, as well as of the maximum aerobic power $\left(\mathrm{V}_{\mathrm{O} 2} \mathrm{max}\right)$ of the whole body. Thus proteomics allows to correlate the locomotor functional 
changes observed in the elderly with changes in abundance of specific metabolic, contractile and stress response proteins granting new insight into the origin of both ultrastructural and functional changes induced by aging. Interestingly, a study [85] on the effects of aging performed on human mitochondria by ICAT labeling and LC MS/MS showed a decrement of most oxidative enzymes. Unfortunately, the authors did not examine simultaneously the protein profile of the whole muscle, leaving unanswered two important functional aspects, i.e., the levels of enzyme activity and the efficiency of the mitochondrial function.

Animal models may be a source of useful information on muscle proteome dysregulation induced by aging and several animal studies were extensively discussed. Aging was investigated comparatively in different rat strains standardized for age on the basis of their life expectancy. Proteomic analysis identified changes correlated to morphological abnormalities in metabolic, contractile and cytoskeletal proteins, a dysregulation of iron homeostasis, a change in $\mathrm{Ca}^{2+}$ balance and in the level of stress response proteins [86]. A recent interesting finding in the rat was a parallel dysregulation, with aging, of the protein pattern of gastrocnemius and of the sciatic nerve controlling it [87]. By analyzing proteomic data from the two tissues, besides dysregulation of the membrane adhesion proteins and of proteins regulating the neuronal caliber, 16 protein isoforms showed a parallel up or down changing trend in nerve and muscle. These findings may imply the existence of a common process acting as a signal event of degeneration in the two tissues. Only $\beta$-enolase and tropomyosin $1 \mathrm{~A}$ were differentially expressed in the two tissues appearing to be specific markers of aging [87].

\subsection{Effects of immobilization}

Prolonged bed rest is known to induce substantial atrophy of lower limb muscles characterized by reduced cross sectional area (CSA) and fascicle length.

The effect of bed rest without and with vibrational exercise countermeasures (RVE) on the proteome was assessed in two groups of subjects by 2D-DIGE and MALDI-ToF MS/MS or ESI MS/MS in two functionally and structurally different muscles: the vastus lateralis (VL) and the soleus (SOL) [88]. SOL is characterized by being a predominantly slow ( 35:65\%) twitch muscle whereas VL is a mixed type II/I ( 50:50\%) muscle. After 55 days of forced bed rest, both VL and SOL underwent in control subjects (CTRL), decrements of $~ 15 \%$ in cross sectional area (CSA) and of $\sim 22 \%$ in maximal torque that were prevented by RVE. MHC distribution showed in CTRL, both in VL and SOL, increased type I and decreased type IIA fibers whereas the opposite was found with RVE. A substantial down regulation of proteins involved in aerobic metabolism characterized both SOL and VL in CTRL, whereas proteins involved in anaerobic glycolysis were up-regulated. RVE reversed the pattern more in VL than in SOL. In the thin filament, changes of contractile proteins involve cardiac and skeletal actins, troponin subunits, LIM domain and myozenin proteins. This functional impairment could profoundly influence the calcium-activated signaling process associated with the $\mathrm{Z}$ disk function. Also the organization of the thin filament appears to be influenced by bed rest. In fact, the end capping protein gelsolin increased during bed rest whereas troponin $\mathrm{T}$ was found to be less abundant, suggesting that the single regulatory units of the thin filament were also perturbed [89]. RVE countermeasures appear to counteract the above described alterations by increasing troponin $\mathrm{T}$ and gelsolin. The disruption of the sarcomeric organization could also be the consequence of a loss of titin as observed in animal models [90]. The latter protein was not detected by the present analysis. Mechanical stress sensors are not limited to the $\mathrm{Z}$-disk region. They are also embedded in muscle-specific membrane systems such as the costamere, intercalated disks, and caveolae-like microdomains (vinculin, desmin, and WD repeat). Indeed, some of the contractile proteins involved in mechanical stress [91], were dysregulated. Proteins from the Z-disk region and from costameres were differently dysregulated during bed rest without and with countermeasures, particularly in VL. RVE appears to counteract these events only partially, and it is difficult to assess if the protocol adopted in this study aimed at counteracting muscle loss, is the most appropriate to restore muscle function. A bioinformatic analysis by IPA software positioned dysregulated molecules in a broader AHR complex negative acute phase response pathway. The stress induces transcriptional activation of genes encoding xenobiotic metabolizing enzymes, phase II metabolizing enzymes (Glutatione-S-Transferase, NADPHquinone oxidoreductase, UDP-glucuronosyl-S-transferase) and other growth factors and proteins involved in cell cycle progression and apoptosis. These events could be mediated by calcium-activated signaling, in particular via calcineurin, whose modulation induces nuclear transcription. With regard to the negative acute response phase mediated by NF-kB signaling, the activation of this pathway supports the possible positive role of a mechanical stress response. The comparison of the metabolic dysregulation pattern induced in the two investigated anatomically and functionally different muscles by bed rest without and with vibration countermeasures provides unique information on the muscle protein signature during prolonged inactivity and, moreover, on the potential benefits of adequate exercise countermeasures to be adopted during and after long-lasting space flights as well as for rehabilitation after trauma of the locomotor apparatus.

The effects of immobilization was also investigated in the rat by differential proteomic analysis after varying duration of hindlimb suspension [92-95]. As observed in humans after prolonged bed rest, remodeling of a postural muscle (the soleus) phenotype, results in a fiber type shift from slow oxidative to fast glycolytic which is paralleled by an increase in muscle fatiguability. 2D-DIGE, mass spectrometry and biochemical assays were applied to assess qualitative and quantitative differences in the proteome of the rat soleus muscle subjected to disuse. The results indicate a modulation of troponin I and of the tropomyosin complex regulating fiber type transition from slow to fast, and suggesting a new role of both the above proteins in the regulation of fiber type transition during unloading. In addition, changes in calcium sensitivity and cooperativity seem to precisely regulate MHC transition from slow to fast phenotypes. Associated with, or induced by unloading, metabolic changes occurring in the atrophied muscle were also detected in the proteome, such as an increment of glycolytic enzymes and a decreased capacity of 
fat oxidation. These metabolic changes appear to be counteracted by acetyl-L-carnitine treatment which restores the mitochondrial mass and decreases glycolytic enzyme expression, suggesting a normalization of the metabolic shift observed after 14 days unloading. This normalization of the metabolic machinery is accompanied by maintenance of body weight and seems to prevent a switch of fiber types. The proteomic data closely agree with what was expected from the loss of function and change in muscle mass and in the body index in this animal model and are also in agreement with the changes observed in the human soleus after 55 days of bed rest [88] contributing to open new avenues for the comprehension of the signaling events responsible for the functional changes observed in unloaded muscles. From the above studies, even if the applied protocols of unloading are different (bed rest in humans us hindlimb suspension in rats), there are hints that results from animal models may parallel human data, particularly when the muscles are characterized by the same fiber type composition and exhibit similar phenotype changes under the same paraphysiological conditions. The finding that acetyl-Lcarnitine supplementation restored the metabolic control of unloaded muscle, might be expected to counteract also the functional impairment of human soleus induced by bed rest. The latter could hopefully be an example of the possibility of transferring to humans results from animal models.

\subsection{Effects of eccentric upper extremity exercise on plasma proteome}

Blood concentrations of creatine kinase (CK), myoglobin, troponin isoforms and lactate dehydrogenase (LDH) are extensively monitored in clinical chemistry as biomarkers of muscle injury [96]. Nevertheless, they remain poorly informative of the muscle status and can't discriminate between a tissue injury or a recent exercise performance. Therefore, the identification of biomarkers able to detect muscle damage in biological fluids, is increasingly needed and new methods able to identify them avoiding the invasive procedure of muscle biopsy, would be very suitable, particularly, for the study of muscle disease. Sietsema et al. [97] adopted, recently, the plasma profile of nine, age- and gender-unmatched volunteers, to identify biomarkers of muscle damage induced by eccentric exercise. Samples also included diabetic patients as an example of chronic disease. Subjects were monitored at 5 different times, before and after the end of exercise. Plasma underwent glycopeptide enrichment, followed by LC MS/MS [98-100]. Potential protein markers with at least 2 distinct peptide components increasing during exercise as a function of work load and duration, were selected. The selection was based on a pair-wise correlation of peptide abundance for all subjects at each time point, and the peptides meeting the requirements were chosen as putative biomarkers. Four proteins were found to meet the criterion: alpha 1 antichymotrypsin (ACT), plasma protease C-1 inhibitor, hemoglobin $\alpha$ and $\beta$ chains, thereby indicating that the detected changes were not spurious variations but were induced by exercise. Across the subjects the fold-change of the four proteins did not correlate with that of the CK levels. A correlation of 3 of them with CK was observed, whereas ACT and $\mathrm{C} 1$ changes, known markers of inflammation, preceded the increment of CK. No differences were detected between normal subjects and diabetic patients. In addition, the limited number of subjects precluded the possibility of identifying specific biomarkers of muscle damage related to aging. The results of this study in healthy subjects indicate that plasma proteomics may have a potential for identifying biomarkers of muscle damage, even though the biological significance of the described changes is still not quite clear. It should be pointed out that a small number of investigated plasma samples and their heterogeneity due to biological variability may hamper tentative correlations of significant markers. By increasing the number of investigated subjects, the number of significant changes may possibly decrease, being likely more than compensated by an increased robustness of the results. Animal models could provide further hints for the detection of new biomarkers of muscle damage in sera, particularly when based on an extensive proteome analysis of muscles differently affected by the disease as is the case for the $\mathrm{mdx}$ animal model [101,102].

\section{Differential proteomics in the study of muscle pathophysiology and pathology}

Disorders affecting muscle function mainly comprise a group of rare diseases with heterogeneous phenotypes, the so called neuromuscular hereditary disorders (NMDs), studied intensively, both in terms of genetic definition and pathophysiology. Other diseases affecting muscle function are the consequence of disorders in which muscle is not the primary target, such as inflammation and diabetes. Regarding the treatment of the above described pathology, most of the ongoing trials are designed to correct or counteract the decline of specific altered functions. To monitor the benefits of a given intervention at the individual level, classical clinical markers of muscle damage such as immunohistochemical alterations, enzyme dysregulation, changes of contractile and transport proteins, are not always sensitive enough for detecting slight changes in disease progression. Differential proteomics, by monitoring more precisely the level of specific markers, could improve diagnosis and the follow-up of these pathologies. The development of genetically engineered animal models can significantly contribute to the definition of some pathophysiological mechanisms of NMDs, particularly of the role of secondary events leading to muscle weakness and early death. With the aid of such models, repeated analyses at different stages of evolution of the primary disease or in the progressive involvement of different muscles are now becoming feasible. This avoids some of the bias deriving from interindividual variability and from restricted sample availability. Dedicated animal models, thanks to their well defined genetic background where the primary defect is imposed, are easily age- and gender-matched, and their nutritional and environmental parameters can be strictly controlled, thereby potentially providing reliable biomarkers of secondary events that could be hopefully extended to the study of NMDs. In addition, parallel investigations in patients and in suitable engineered animal models, could be useful to make it possible to translate some findings from animals to humans. Indeed, protein profiles of muscle diversity in patients and animal 
models, after standardizing for age and for the effects of immobilization, can facilitate phenotype comparison and correlation of specific datasets, allowing to identify significant molecules for monitoring. Development of new animal models shall contribute to improve the knowledge of rare human muscle diseases as well as of the features of their progression, thereby avoiding recurring invasive analyses in patients that are necessarily limited on ethical and technical grounds. Unfortunately, despite the number of investigations on $m d x$ animal models [102] which largely contributed to the comprehension of pathophysiological mechanisms associated with lack of dystrophin, as far as we know, no investigations on the human muscle proteome were conducted on the Duchenne muscular dystrophy. What follows is a summary of the proteomic studies carried out in NMD patients and in type 2 diabetes over the last years.

\subsection{Dysferlinopathies}

To clarify the physiopathology of an important NMD disease affecting sarcolemmal membrane integrity, a differential proteome analysis of the quadriceps muscle of patients affected by a dysferlinopathy in comparison with healthy control individuals was conducted [103]. Biopsies were obtained from 9 patients and 6 healthy control subjects. To improve the detectability of isoform distribution of contractile proteins, the samples were analyzed in a 3-10 NL pH gradient and in a narrow acidic range, $\mathrm{pH}$ 4.5-5.5, and gels were quantitated. Mutations in the gene for dysferlin (Dystrophy associated fer-1like protein) cause muscular dystrophy in humans, such as the limb-girdle muscular dystrophy type 2B (LGMD2B) and the distal muscular dystrophy of Miyoshi (MM) [104]. The dysferlin gene encodes a type II membrane-associated protein belonging to the ferlin family, which is localized in the sarcolemma and implicated in calcium dependent phosopholipid binding $[105,106]$. Dysferlin interacts with caveolin-3 and seems to be involved in the mechanism of membrane fusion and repair. Genetically, the disorder is well characterized. In muscles of patients affected by LGMD2B or MM, an inflammatory response associated with fiber degeneration and myopathology is frequently observed, whose origin, however, is unknown. Though clinical symptoms of the disease occur in the second decade, damage to muscle ultrastructure and changes of CK levels are already evident before their appearance. Muscle regeneration interferes with inflammatory response and disease progression. Signs of muscle regeneration were shown preceding inflammation and complement cascade activation [107]. A disruption of the muscle repair machinery seems to be responsible for dysferlin-deficient muscle degeneration, highlighting the importance of the cellular mechanisms of membrane integrity in the pathogenesis of the disease [108]. Several markers related to protein synthesis and folding and heat shock protein 90 (P08238), were found to be up-regulated in patients, suggesting that an increased protein synthesis could be related to muscle regeneration [108]. Metabolic proteins appear to be dysregulated with proteins involved in respiratory chain activity being more abundant and glycolytic enzymes such as $\alpha$-enolase and phosphoglyceromutase less abundant in patients. Alterations in contractile proteins suggested a defect in the actin bundle formation with a decrement of $\alpha$-actin and an increment of $\alpha$-actinin known to anchor actin to the intracellular structures, and of WD-repeat protein 1 involved in actin filament disassembly [109,110]. These changes may be due to the impairment of the membrane protein repair system characteristic of dysferlinopathies. Patients also display an anomalous behavior of regulatory myosin light chains (MLC) affecting both slow and fast fibers. The quantitative evaluation of the corresponding spots in muscle samples from patients indicates a switching from fast to slow twitch fiber types and a reduction of the phosphorylatable isoforms in the fast fibers. The latter change is known to be responsible for a reduction of the maximal contractile velocity and force by the muscle [82], hence, the patient's functional impairment. The described study raises the questions of how to discriminate between protein changes induced by disuse as opposed to inflammation, and of the relationships of the latter with dysregulated proteins typical of the primary defect (Fig. 9). Indeed, only an extensive comparative study of different diseases affecting a specific component of the contractile machinery could generate adequate data, making it feasible to associate given sets of biomarkers with specific diseases.

\subsection{Facioscapulohumeral muscular dystrophy}

As previously stated, NMDs are a genetically well defined set of disorders. A disease representing an exception to this nosographic classification is the autosomal dominant facioscapulo humeral dystrophy (FSHD). In fact, the defect is not only linked with a mutation in a specific, recently identified [111] gene (DUX4), but is also correlated to the arrangement of the telomeric region D4Z4. FSHD is caused by the deletion of an integral number of 3.3-kb KpnI repeats inside the telomeric region D4Z4 at the $4 \mathrm{q} 35$ locus. Despite the identification of the molecular mutation, the role of the D4Z4 arrangement is still under debate. In its classical symptomatology, FSHD is characterized by early involvement of facial and scapular muscles. However, besides being characterized by variable penetrance, this condition presents a wide and heterogeneous spectrum of clinical features. Immunohistochemistry and a muscle specific cDNA microarray platform were combined with proteomic data to analyze muscle samples of patients characterized by a variable number of KpnI repeats [31]. Unsupervised cluster analysis divided patients into three classes according to their KpnI repeat number, suggesting a role for the D4Z4 arrangement in transcriptional and proteomic pattern changes. Among the scapular muscles, the deltoideus, is the least affected, exhibiting minimal to mild myopathic symptoms in all patients, so that protein and transcript changes could reasonably be attributed to the primary genetic defect rather than to the underlying pathology. Alterations in the expression levels of transcripts and proteins controlled by the musclespecific transcription factor MyoD were detected, and the level of impairment in differentiation from slow to fast muscle fibers was found to correlate to the size of the contracted D4Z4 region. The above results suggest that crucial factors in disease progression could be defects in the MyoD-dependent gene network and in cell differentiation. Proteomics indicates that cell cycle regulators are reduced, among the latter, the NEDD8 gene product. This is a ubiquitin-like post-translational modifier that is covalently linked to the cullin (Cul)-family proteins, 


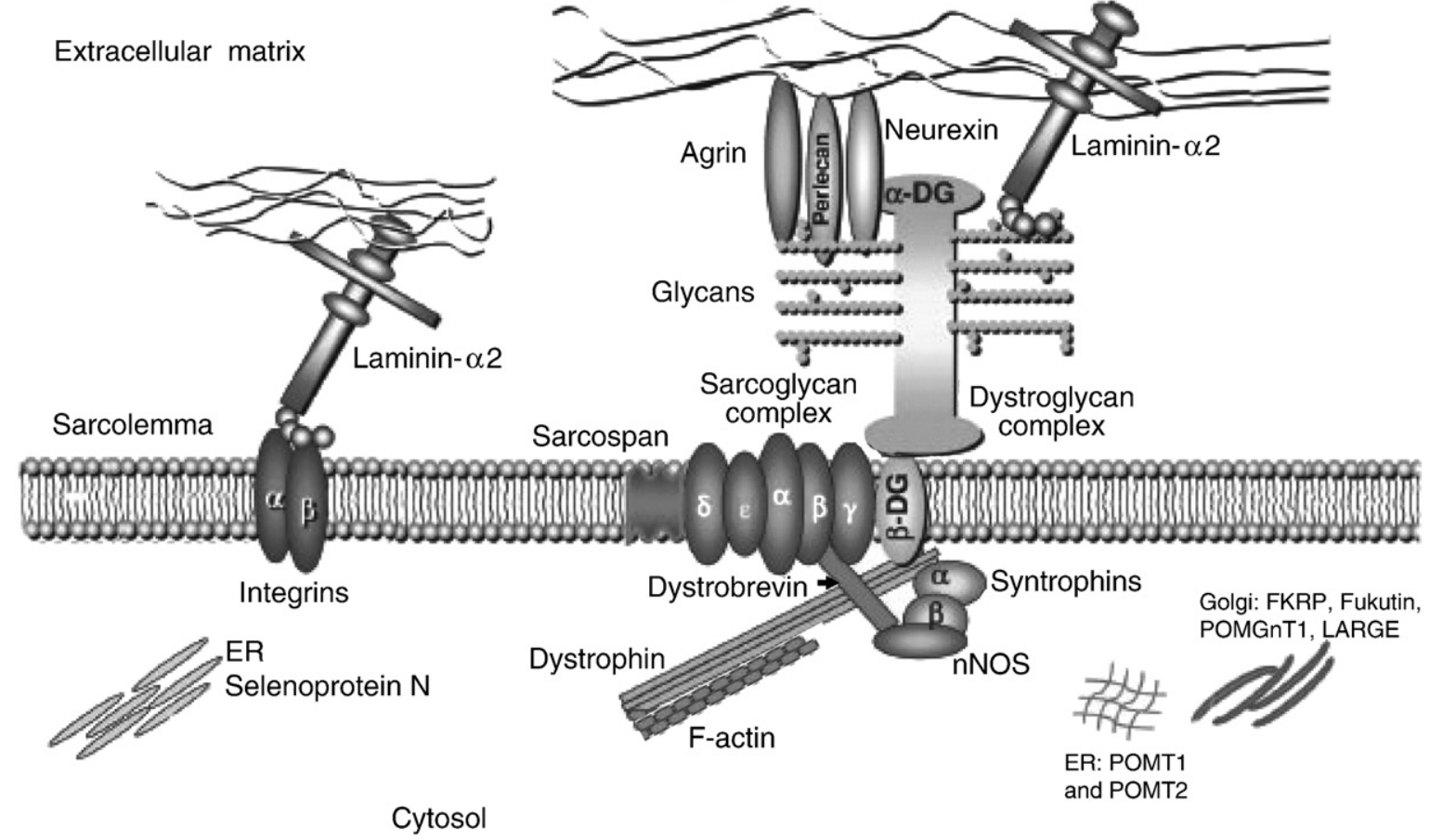

Fig. 9 - Schematic representation of the dystrophin-associated protein complex. The distrophin complex is an assembly of proteins that connect inner cytoskeleton with extracellular matrix.

known to enhance ubiquitinating activity and to play a central role in differentiation via degradation of cell cycle regulators [112] and of Hsp70, involved in cyclin maturation [113]. The nuclear transcription factor NF-kB, regulated by NEDD8 activity is also increased and may induce further loss of MyoD mRNA in FSHD muscle, thereby interfering with skeletal muscle differentiation. With regard to fiber type composition, transcriptional, proteomic and histochemical analyses, support the presence of an increased number of slow type I fibers in severely affected muscles of FSHD patients. The changed proportion of these fibers may be the result of an adaptation to the disease, or of an adult muscle's failure to properly regenerate. This fiber type shift is compatible with comparative differential proteomic data of human muscles in aging, except that MLC phosphorylated isoforms are unchanged in FSHD patients contrary to healthy elderly subjects despite the similar distribution of $\mathrm{MHC}$ suggesting that fiber type switching is under different upstream regulators. In addition, most proteins involved in oxidative stress responses are decreased according to the number of KpnI repeat units, which reflects a progressive inability of the antioxidant defenses to maintain cellular homeostasis. The changed expression of the $\mathrm{Ca}^{2+}$-dependent transcription factors NFATs and MEF2C and of signaling molecules such as calmodulin and troponin C, probably amplifies the degenerative process. From these results it may be concluded that D4Z4 contraction may affect the expression of transcription factors involved in myogenesis with implications for the function of the regeneration pathway of satellite cells in adult tissue. Parallel proteomic studies on FSHD animal models might be suitable for validating some of the hypotheses put forward by investigations on patients.

\subsection{Inclusion body myositis (IBM)}

Three studies from different groups adopted the proteomic approach to investigate inclusion body myositis, an inflammatory disease of skeletal muscle of unknown origin. The first two studies didn't reach the goal due to a limited number of patients and an insufficient amount of muscle samples [114-116]. To better understand the nature of the tissue injury in this disease, a further study including immunohistochemistry, gene expression profile and proteomic analysis was performed on 17 patients with inflammatory myopathies and on 3 elderly healthy control subjects [117]. A loss of fast twitch fibers, sarcomeric proteins and glycolytic enzymes was found. Protein profiling was obtained adopting tryptic digestion after protein extraction and HPLC ESI MS/MS. Approximately 10.000 spectra were collected per LC/MS run, and row files were converted to Mascot and searched against the human international protein index database. All matches were manually curated [118]. Two distinct peptides were required for protein identification and spliced isoforms of the same gene were not considered. Identified peptides were assigned consistently to the smallest possible list of identified muscle proteins due to their large number of shared peptides [119]. A gene expression profile was conducted on 31 samples, which also included different diseases such as polymyositis (PM) and dermatomyositis (DM) using the Affymetrix platform representing 18,000 genes. Samples were characterized by immunohistochemistry, adopting ATP ase and specific antibodies toward MHC isoforms for fiber typing and antibodies for glycogen debranching amylo1,6-glucosidase and alpha actinin-3 assessment. Proteomic analysis identified 300 distinct proteins in each biopsy and 
reproducibility was assessed in quadruplicate by LC MS/MS on each sample by dividing it into 4 pieces. Intra sample reproducibility was high. However, large inter-individual variability was observed. Proteomic results indicate a loss of fast twitch isoforms of muscle proteins accompanied by a decrement of structural proteins such as actinin 3, troponin type 3, myozenin, myomesin 2 and MLC 1. The loss of fast twitch isoforms was present in all inflammatory myopathic patients, and the same loss of fast fibers was observed, even though to a lesser extent, in PM and in DM. Comparisons with the results obtained in other inflammatory diseases were made by immunohistochemistry. Regeneration was also present with a great increment (18 fold) of myosin heavy chain H3 (embryonic myosin). The latter was common to PM and DM as confirmed by immunohistochemistry. Metabolic proteins were dysregulated with a reduction of 4 glycolytic enzymes, the greatest reduction being observed for the glycogen debranching amylo-1,6-glucosidase also common to PM and DM. By contrast, $\alpha$-glucagone transferase was specific for IBM. Laminin-A/C was decreased, whereas immunoglobulin heavy chains and $\alpha$-filamin, a substrate of calpain-3, were more abundant in these patients. Laminin decrement may reflect nuclear degeneration whereas the abundance of immunoglobulin may reflect infiltration of $\beta$-cells into muscle. Several components of the extracellular matrix were also overexpressed in agreement with the found fibrosis and the presence of connective tissue. Limitations of this extensive study were admitted by the authors who couldn't identify either $\beta$-amiloid precursors or titin and collagen which, by contrast, were found in abundance in diseased and normal samples by immunohistochemistry. The authors concluded that the adopted proteomic platform was less sensitive than immunohistochemistry. However, it should be pointed out that proteomics is an unbiased approach and even if it failed to detect some of the proteins known to be changed in inflammatory diseases, it could identify filamin A and the AHNAK, a nucleoprotein involved in subsarcolemmal cytoarchitecture and membrane repair. The latter, known to interact with dysferlin and, together with filamin A, a substrate of calpain-3, is accumulated through calpain deficiency [120]. The major concern of the authors was the variability in protein abundances even among samples of patients affected by the same disease. This finding likely reflects the many confounding variables, such as age and gender, severity of the disease, chronicity, and other factors characteristic of each particular patient, making a differential study extremely complex. The choice of samples to be compared, e.g. normal us diseased, or a different severity of the investigated conditions, or differences between diseases characterized by similar phenotypes, as well as the choice of an adequate technological approach and of the procedures to validate differential results, represent factors that cannot be disregarded.

\subsection{Dermatomyositis with muscle perifascicular atrophy}

Dermatomyositis (DM) is an autoimmune disease primarily involving muscle and skin [121,122]. Recent microarray studies have pointed toward a mechanism of tissue injury associated with the overexpression of type 1 interferoninducible gene $[123,124]$. Interferon-stimulated gene 15 (ISG15) conjugated proteins in DM muscle with muscle perifascicular atrophy, were investigated by Salajeheh et al. [123]. ISG15 is a poorly understood ubiquitin-like modifier. The enzymatic pathway for ISG15 conjugation to a target protein involves three conjugating and one deconjugating enzymes [125-128]. The conjugation of ISG15 to proteins in human tissue samples has been reported in colon cancer but the identity of such proteins remains unknown [129]. The above study included 113 patients with a variety of muscle diseases, 76 were affected by immune-mediated inflammatory myopathies, 26 by non-inflammatory myopathies and 11 had no evidence of neuromuscular disorders. Microarrays, immunohistochmistry and proteomics were utilized to analyze the samples. Proteomics was performed using LC MS/MS on muscle biopsy extracts and on muscle cells after laser capture dissection. Microarrays indicate that transcripts encoding for ISG-15 conjugation pathway proteins were markedly upregulated in DM with perifascicular atrophy. Free ISG- and ISG-conjugated proteins were only found on immunoblots after SDS from DM patients. Cellular cultures of human skeletal muscle exposed to type 1 interferon produced similar transcripts, ISG15 proteins and conjugates. In addition, laser capture microdissection followed by proteomic analysis showed a number of dysregulated proteins such as nebulin, troponin, myomesin, Zasp, MHC slow and fast isoforms, myosin binding protein $\mathrm{C}$, voltage-dependent anion channel, myotilin, CK, fatty acid binding protein, glyceraldehyde 3phosphate dehydrogenase, carbonic anydrase, peroxiredoxin, and Hsp70, whose changes were common to other diseases. Peculiar of DM patients with perifascicular atrophic myofibers was a deficiency of titin. The latter result appears to be the most peculiar feature of the disease. Unfortunately, the study has failed to detect ISG15-conjugated proteins both in cell cultures and in muscle tissue.

As it appears from the above paragraphs, proteomics can profile secondary events related to primary NMDs, thereby providing insight into the muscle ability to cope with dysfunctional proteins or the effects of inflammation. For instance, muscle regeneration characterized by overexpression of embryonic MHC and associated with metabolic adaptations, as assessed by proteomic analysis, represents one of the primary events whose absence is accompanied by muscle loss. Inflammation is associated to a typical dysregulation of the proteome, whose main feature is the decrement of antioxidant enzymes preventing muscle tissue to buffer ROS production and to control $\mathrm{Ca}^{2+}$ unbalance, thereby inducing fiber switching from fast to slow type. Selected subproteome analysis, (e.g. of organelles and membranes, of posttranslational modifications, of silencing of specific genes, of responses to different pharmacological treatments), could shed light on the physiopathological mechanisms specific of or associated to a given disease. The extension of proteomic studies to new, well characterized, pertinent animal models is recommended for further investigations in human pathology.

\subsection{Insulin resistance}

The first investigation adopting the 2DE approach aimed to identify biomarkers was applied to the differential analysis of skeletal muscles of patients affected by insulin resistance [45]. The latter condition is typical of type 2 diabetes mellitus (T2DM) 
patients and is known to be related to a reduction of nonoxidative glucose metabolism in muscle accompanied by an impairment in glucose oxidation and by suppression of lipid oxidation after insulin stimulation [130-132]. These features suggest an altered capacity to switch between carbohydrate and fat as an oxidative energy source due to impaired mitochondrial metabolism [133-137] and altered signaling of known sensors of energy stress imbalance, such as AMPactivated protein kinase (AMPK) [138] by way of the transcriptional co-activator of peroxisome proliferator activated receptor, PGC- $1 \alpha$. The latter is known to promote mitochondrial biogenesis and to increase the glucose transporter type 4 (GLUT4) protein content in muscle [139-141]. The finding of a general decrement of oxidative capacity in the whole muscle mass of T2DM patients rules out the possibility that the above change is attributable to an increased proportion of type 2 muscle fibers [142]. In order to identify markers of T2DM in the fasting state, a differential proteomic study utilizing 2DE and mass spectrometry was performed on the vastus lateralis muscle of 10 obese patients with T2DM, where 5 were treated with diet and 5 with low doses of either sulfonylurea or metformin, and 10 healthy age- and gender-matched control subjects. 15 proteins were found differentially expressed in the two groups and 11 of them were identified by mass spectrometry, i.e. 3 metabolic enzymes: ATP Synthase-subunit $\beta$ (ATP Sin $\beta)$ and brain creatine kinase (CK-B) which were down regulated, and phosphoglucomutase (PGM-1) which was increased in patients; 2 heat shock proteins, Hsp90 $\beta$ and GRP78, which were up-regulated in patients; different isoforms of structural proteins, i.e. 4 isoforms of $\alpha-1$ chain of type VI collagen $(\alpha 1$ (VI)) and one isoform of MLC2 which were also up-regulated, whereas one isoform of MLC2 was down-regulated. A number of correlations were attempted both in T2DM patients and control subjects, e.g., among: a) protein markers such as ATP $\operatorname{Sin} \beta, C K-B$ and $\alpha 1$ (VI) and fasting plasma glucose levels; b) ATP Sin $\beta$ and CK-B and FFA levels; and c) PGM-1 and insulin levels, body mass index, etc. The results appear rather weak and are characterized by large variability, possibly due to the relatively small number of investigated subjects. Interestingly, a study of phosphorylated isoforms of protein markers in T2DM patients was also conducted by 2DE in [32P]-phospholabeled human myoblasts. It revealed that a number of differentially expressed proteins were phosphorylated and that post-translationally modified isoforms followed the up- or down-regulation of the corresponding protein. Whether the above described and other significant changes are secondary to hyperglycemia, hyperinsulinemia, altered muscle fiber type composition or whether they are indicative of a primary metabolic defect in T2DM patients remain matters for investigation.

Hwang et al. performed an extensive proteome differential analysis in 3 groups of 8 subjects each, comprising healthy lean and obese subjects and T2DM patients, adopting 1D electrophoresis followed by HPLC ESI MS/MS [143]. Muscle proteins were quantitated using normalized spectral abundance factor methods (NSAFs). When the results for all 24 subjects were combined, 1218 proteins were identified. Proteins that were found in at least half of all participants totaled 400, of which 92 were increased or decreased by a factor of 2 in at least one of the 3 possible two group-comparisons (obese us lean, diabetic us lean, and diabetic us obese). Of the 92 altered proteins, 15 were significantly different among the investigated groups by one way ANOVA $(p<0.05)$. Proteins with decreased abundance in T2DM patients were different from those identified in a previous study [45]. The authors pointed out the limits of their work (subjects were not age-matched with controls, weak statistical analysis) that was considered only a starting point for additional more focused investigations designed to test the hypotheses put forward by their previous findings. Comparing results of the two reported proteomic studies on T2DM patients, the first conclusion that can be drawn, is the higher sensitivity of 1D HPLC ESI MS/MS for protein identification compared with 2DE but the lower robustness of the differential analysis.

Animal models were also adopted to evaluate protein expression changes associated with type 1 diabetes. Johnson et al. investigated by 2DE the protein expression of liver, heart and skeletal muscle of diabetes-prone rats [144]. The study provided interesting observations e.g., the limited involvement of skeletal muscle in this disease. In fact, only 9 proteins were found to be differentially expressed in the muscle compared to 341 proteins changed in the liver. These results are consistent with the known large alterations in liver metabolism associated with a lack of insulin, mimicking systemic starvation. In a recent paper, Ohlendieck et al. [145] adopted the GK rat model of type 2 diabetes [146], a spontaneously non-obese diabetic animal exhibiting chronic impaired insulin signaling, to investigate changes in the proteome of the gastrocnemius. The latter muscle was characterized by decreased recruitment of the glucose transporter GLUT 4, abnormal mitochondrial functioning and reduced population of slow-twitch fibers. The proteome of this animal exhibited a limited number of protein changes and the diabetes-related changes of metabolic enzymes were particularly moderate. Among the 7 decreased proteins, carbonic anhydrase 3 and hydroxy-isobutyrate dehydrogenase were the most relevant. Mitochondrial markers, apart from dihydrolipoamide succinyl transferase, were increased. Also glycolytic enzymes were at variance. Whereas it appears difficult to figure out how insulin resistance triggers these altered enzyme expression patterns, the found changes in enzyme abundance could certainly modify the glycolytic flux in diabetic muscle. In this model, the most altered enzyme was the monoglyceride lipase. In analogy with human data, adenylate kinase 1 was increased as were the mechanisms aimed to counteract dysregulation of thin filaments with increments of $\alpha$-actin and of the capping protein of the actin filament. Increased levels of stress-response proteins and anti-oxidant markers, such as the small heat shock protein Hsp27/B1, of 3-mercaptopyruvate sulfurtransferase and Cu/Zn superoxide dismutase, were observed, hence the need to counteract diabetes-induced cellular damage. This was the first study on this rat model. Further efforts should be made to better characterize the above described pathophysiological mechanisms, even though the adopted mild phenotype could be a limitation for a direct correlation with human data. In a following study on rat gastrocnemius muscle by 2DE [147], the effect of the treatment with fenofibrate, a drug used to treat high cholesterol and triglyceride levels, was investigated. The latter acts as an agonist of PPAR- $\alpha$, a transcriptional factor regulating gene expression playing an important role in activating many proteins catalyzing lipid metabolism, and 
with a considerable impact on insulin sensitivity in diabetes. Many proteins were found to be influenced by the treatment, particularly the c11orf 59 protein (whose function is unknown) and the signal protein phosphatidylethanolamine binding protein and IkB-interacting protein. The authors hypothesized that the identified proteins were involved in controlling lipid or carbohydrate metabolism in diabetes via PPAR- $\alpha$ activation. This hypothesis appears to be preliminary and requires further validations, particularly in patients.

\section{Conclusions}

Notwithstanding its obvious limits, this review features most of the work that has been carried out in human muscle proteomics from the onset of research in this area. Along with genomics, proteomic technologies (adopting all available methods) represent so far the most powerful means for a systematic characterization (separation and identification) of muscle proteins. In fact, it has made it possible to describe the status of both contractile and metabolic proteins and of their changes for a wide range of physiological, paraphysiological and pathological conditions. Proteomics highlights the various aspects of plasticity of muscles which are ultrastructurally and functionally greatly diverse. Comparative or differential proteomics has allowed the unraveling of some of the most specific metabolic adjustments occurring in muscles, as a function of exercise mode (e.g. aerobic us anaerobic), of changes of environmental conditions (hypoxia, simulated hypogravity, thermal adaptation, etc.), feeding and overfeeding, gender, ethnic characteristics and of aging. Throughout this review, which deals mainly with human proteomics, data from animal models have been occasionally reported when human data were totally missing or results from animal studies, carried out on similar experimental protocols, were available for comparison. From these studies new hypotheses could be put forward and trends, toward biomarkers discovery and modulation, identified. After having set the baselines in healthy volunteers, a pre-requisite for the study of pathology, proteomic technologies were also applied to analyze several diseased muscles. Unfortunately, so far, the adoption of differential proteomics in pathology, despite its high potential, revealed its frailty, particularly because of the frequent use of unspecified muscles and/or of unmatched samples. Indeed, the selection of the former and the correct choice of the latter are fundamental requirements for identifying new biomarkers. On the other hand, the current and future development of pharmacoproteomics, by making it possible to act on altered nodes in the muscle biochemical machinery, shall allow to counteract a progressively greater number of secondary pathologic consequences of genetic muscle diseases.

\section{Acknowledgements}

This work was supported by the Italian Ministry of University and Scientific Research (grant FIRB RBRN07BMCT to C.G), EU community (grant BIO-NMD N. 241665 to C.G), Telethon foundation (grant N. GGP08107D to C.G) and Agenzia Spaziale Italiana (A.S.I. OSMA Project n 1/007/06/0 Work Package 1B141 to P.C.).

\section{R E F E R E N C E S}

[1] Buller AJ, Eccles JC, Eccles RM. Interactions between motoneurones and muscles in respect of the characteristic speeds of their responses. J Physiol 1960;150:417-39.

[2] Pette D, Wimmer M, Nemeth P. Do enzyme activities vary along muscle fibres? Histochemistry 1980;67:225-31.

[3] Pette D. Historical perspectives: plasticity of mammalian skeletal muscle. J Appl Physiol 2001;90:1119-24.

[4] Haddad F, Qin AX, Bodell PW, Zhang LY, Guo H, Giger JM, et al. Regulation of antisense RNA expression during cardiac MHC gene switching in response to pressure overload. Am J Physiol Heart Circ Physiol 2006;290:H2351-61.

[5] Weiss A, Schiaffino S, Leinwand LA. Comparative sequence analysis of the complete human sarcomeric myosin heavy chain family: implications for functional diversity. J Mol Biol 1999;290:61-75.

[6] Staron RS, Pette D. The multiplicity of combinations of myosin light chains and heavy chains in histochemically typed single fibres. Rabbit soleus muscle. Biochem J 1987;243: 687-93.

[7] Pette D, Staron RS. Mammalian skeletal muscle fiber type transitions. Int Rev Cytol 1997;170:143-223.

[8] Pette D, Staron RS. Myosin isoforms, muscle fiber types, and transitions. Microsc Res Tech 2000;50:500-9.

[9] Stephenson GM. Hybrid skeletal muscle fibres: a rare or common phenomenon? Clin Exp Pharmacol Physiol 2001;28: 692-702.

[10] Caiozzo VJ, Baker MJ, Huang K, Chou H, Wu YZ, Baldwin KM. Single-fiber myosin heavy chain polymorphism: how many patterns and what proportions? Am J Physiol Regul Integr Comp Physiol 2003;285:R570-80.

[11] Stevens L, Bastide B, Mourier Y. Muscle plasticity and variations in myofibrillar protein composition of mammalian muscle fibers. Skeletal Muscle Plasticity in Health and Diseases: From Genes to Whole Muscle; 2006. p. 213-64.

[12] D'Antona G, Pellegrino MA, Adami R, Rossi R, Carlizzi CN, Canepari $\mathrm{M}$, et al. The effect of ageing and immobilization on structure and function of human skeletal muscle fibres. J Physiol 2003;552:499-511.

[13] Stevens L, Bastide B, Bozzo C, Mounier Y. Hybrid fibres under slow-to-fast transformations: expression is of myosin heavy and light chains in rat soleus muscle. Pflugers Arch 2004;448: 507-14.

[14] Larsson L, Moss RL. Maximum velocity of shortening in relation to myosin isoform composition in single fibres from human skeletal muscles. J Physiol 1993;472:595-614.

[15] Schiaffino S, Reggiani C. Molecular diversity of myofibrillar proteins: gene regulation and functional significance. Physiol Rev 1996;76:371-423.

[16] Ebashi SN. Proteins of the myofibril. The structure and function of muscle; 1973.

[17] Fitts RH, Riley DR, Widrick JJ. Physiology of a microgravity environment invited review: microgravity and skeletal muscle. J Appl Physiol 2000;89:823-39.

[18] Bamman MM, Ragan RC, Kim JS, Cross JM, Hill VJ, Tuggle SC, et al. Myogenic protein expression before and after resistance loading in 26- and 64-yr-old men and women. J Appl Physiol 2004;97:1329-37.

[19] Pette D, Staron RS. Cellular and molecular diversities of mammalian skeletal muscle fibers. Rev Physiol Biochem Pharmacol 1990;116:1-76.

[20] Schiaffino S, Sandri M, Murgia M. Signaling pathway controlling muscle fiber size and type in response to nerve activity. In: Springer, editor. Skeletal Muscle Plasticity in Health and Diseases: From Genes to Whole Muscle 2006. p. 91-119. 
[21] Mammucari C, Schiaffino S, Sandri M. Downstream of Akt: FoxO3 and $\mathrm{mTOR}$ in the regulation of autophagy in skeletal muscle. Autophagy 2008;4:524-6.

[22] Giometti CS, Anderson NG, Anderson NL. Muscle protein analysis. I. High-resolution two-dimensional electrophoresis of skeletal muscle proteins for analysis of small biopsy samples. Clin Chem 1979;25:1877-84.

[23] Giometti CS, Barany M, Danon MJ, Anderson NG. Muscle protein analysis. II. Two-dimensional electrophoresis of normal and diseased human skeletal muscle. Clin Chem 1980;26:1152-5.

[24] Giometti CS, Anderson NG. Muscle protein analysis. III. Analysis of solubilized frozen-tissue sections by twodimensional electrophoresis. Clin Chem 1981;27:1918-21.

[25] Gelfi C, De Palma S, Cerretelli P, Begum S, Wait R. Twodimensional protein map of human vastus lateralis muscle. Electrophoresis 2003;24:286-95.

[26] Yan JX, Wait R, Berkelman T, Harry RA, WestbrookJA, Wheeler $\mathrm{CH}$, et al. A modified silver staining protocol for visualization of proteins compatible with matrix-assisted laser desorption/ ionization and electrospray ionization-mass spectrometry. Electrophoresis 2000;21:3666-72.

[27] Hu L, Ye M, Jiang X, Feng S, Zou H. Advances in hyphenated analytical techniques for shotgun proteome and peptidome analysis-a review. Anal Chim Acta 2007;598:193-204.

[28] Li X, Gong Y, Wang Y, Wu S, Cai Y, He P, et al. Comparison of alternative analytical techniques for the characterisation of the human serum proteome in HUPO Plasma Proteome Project. Proteomics 2005;5:3423-41.

[29] Hojlund K, Yi Z, Hwang H, Bowen B, Lefort N, Flynn CR, et al. Characterization of the human skeletal muscle proteome by one-dimensional gel electrophoresis and HPLC-ESI-MS/MS. Mol Cell Proteomics 2008;7:257-67.

[30] Yi Z, Bowen BP, Hwang H, Jenkinson CP, Coletta DK, Lefort N, et al. Global relationship between the proteome and transcriptome of human skeletal muscle. J Proteome Res 2008;7:3230-41.

[31] Celegato B, Capitanio D, Pescatori M, Romualdi C, Pacchioni B, Cagnin S, et al. Parallel protein and transcript profiles of FSHD patient muscles correlate to the D4Z4 arrangement and reveal a common impairment of slow to fast fibre differentiation and a general deregulation of MyoDdependent genes. Proteomics 2006;6:5303-21.

[32] Parker KC, Walsh RJ, Salajegheh M, Amato AA, Krastins B, Sarracino DA, et al. Characterization of human skeletal muscle biopsy samples using shotgun proteomics. J Proteome Res 2009;8:3265-77.

[33] Schiaffino S, Sandri M, Murgia M. Activity-dependent signaling pathways controlling muscle diversity and plasticity. Physiology (Bethesda) 2007;22:269-78.

[34] Guttridge DC. Signaling pathways weigh in on decisions to make or break skeletal muscle. Curr Opin Clin Nutr Metab Care 2004;7:443-50.

[35] Frank D, Kuhn C, Katus HA, Frey N. The sarcomeric Z-disc: a nodal point in signalling and disease. J Mol Med 2006;84: 446-68.

[36] Hojlund K, Bowen BP, Hwang H, Flynn CR, Madireddy L, Geetha T, et al. In vivo phosphoproteome of human skeletal muscle revealed by phosphopeptide enrichment and HPLC-ESI-MS/MS. J Proteome Res 2009;8:4954-65.

[37] Lefort N, Yi Z, Bowen B, Glancy B, De Filippis EA, Mapes R, et al. Proteome profile of functional mitochondria from human skeletal muscle using one-dimensional gel electrophoresis and HPLC-ESI-MS/MS. J Proteomics 2009;72: 1046-60.

[38] Zhao X, Leon IR, Bak S, Mogensen M, Wrzesinski K, Hojlund $\mathrm{K}$, et al. Phosphoproteome analysis of functional mitochondria isolated from resting human muscle reveals extensive phosphorylation of inner membrane protein complexes and enzymes. Mol Cell Proteomics 2010 (Electronic publication ahead of print).

[39] Unlu M, Morgan ME, Minden JS. Difference gel electrophoresis: a single gel method for detecting changes in protein extracts. Electrophoresis 1997;18:2071-7.

[40] Tonge R, Shaw J, Middleton B, Rowlinson R, Rayner S, Young $\mathrm{J}$, et al. Validation and development of fluorescence twodimensional differential gel electrophoresis proteomics technology. Proteomics 2001;1:377-96.

[41] Capitanio D, Vigano A, Ricci E, Cerretelli P, Wait R, Gelfi C. Comparison of protein expression in human deltoideus and vastus lateralis muscles using two-dimensional gel electrophoresis. Proteomics 2005;5:2577-86.

[42] Gelfi C, De Palma S, Ripamonti M, Eberini I, Wait R, Bajracharya A, et al. New aspects of altitude adaptation in Tibetans: a proteomic approach. FASEB J 2004;18:612-4.

[43] Gelfi C, Vigano A, Ripamonti M, Pontoglio A, Begum S, Pellegrino MA, et al. The human muscle proteome in aging. J Proteome Res 2006;5:1344-53.

[44] Hittel DS, Hathout Y, Hoffman EP, Houmard JA. Proteome analysis of skeletal muscle from obese and morbidly obese women. Diabetes 2005;54:1283-8.

[45] Hojlund K, Wrzesinski K, Larsen PM, Fey SJ, Roepstorff P, Handberg A, et al. Proteome analysis reveals phosphorylation of ATP synthase beta-subunit in human skeletal muscle and proteins with potential roles in type 2 diabetes. J Biol Chem 2003;278:10436-42.

[46] Vigano A, Ripamonti M, De Palma S, Capitanio D, Vasso M, Wait R, et al. Proteins modulation in human skeletal muscle in the early phase of adaptation to hypobaric hypoxia. Proteomics 2008;8:4668-79.

[47] De Palma S, Ripamonti M, Vigano A, Moriggi M, Capitanio D, Samaja M, et al. Metabolic modulation induced by chronic hypoxia in rats using a comparative proteomic analysis of skeletal muscle tissue. J Proteome Res 2007;6:1974-84.

[48] Bosworth CAt, Chou CW, Cole RB, Rees BB. Protein expression patterns in zebrafish skeletal muscle: initial characterization and the effects of hypoxic exposure. Proteomics 2005;5:1362-71.

[49] Vogtel M, Michels A. Role of intermittent hypoxia in the treatment of bronchial asthma and chronic obstructive pulmonary disease. Curr Opin Allergy Clin Immunol 2010;10: 206-13.

[50] Johnson MA, Polgar J, Weightman D, Appleton D. Data on the distribution of fibre types in thirty-six human muscles. An autopsy study. J Neurol Sci 1973;18:111-29.

[51] Rosler K, Hoppeler H, Conley KE, Claassen H, Gehr P, Howald $H$. Transfer effects in endurance exercise. Adaptations in trained and untrained muscles. Eur J Appl Physiol Occup Physiol 1985;54:355-62.

[52] Caiozzo VJ, Haddad F, Baker MJ, Herrick RE, Prietto N, Baldwin KM. Microgravity-induced transformations of myosin isoforms and contractile properties of skeletal muscle. J Appl Physiol 1996;81:123-32.

[53] Gelfi C, Vigano A, De Palma S, Ripamonti M, Begum S, Cerretelli $\mathrm{P}$, et al. 2-D protein maps of rat gastrocnemius and soleus muscles: a tool for muscle plasticity assessment. Proteomics 2006;6:321-40.

[54] Simonsen L, Bulow J, Madsen J, Christensen NJ. Thermogenic response to epinephrine in the forearm and abdominal subcutaneous adipose tissue. Am J Physiol 1992;263:E850-5.

[55] Astrup A, Bulow J, Madsen J, Christensen NJ. Contribution of BAT and skeletal muscle to thermogenesis induced by ephedrine in man. Am J Physiol 1985;248:E507-15.

[56] Wijers SL, Schrauwen P, Saris WH, van Marken Lichtenbelt WD. Human skeletal muscle mitochondrial uncoupling is associated with cold induced adaptive thermogenesis. PLoS ONE 2008;3:e1777. 
[57] Wijers SL, Smit E, Saris WH, Mariman EC, van Marken Lichtenbelt WD. Cold- and overfeeding-induced changes in the human skeletal muscle proteome. J Proteome Res 2010;9: 2226-35.

[58] Christiansen E, Garby L. Prediction of body weight changes caused by changes in energy balance. Eur J Clin Invest 2002;32:826-30.

[59] Holloway KV, O\Gorman M, Woods P, Morton JP, Evans L, Cable NT, et al. Proteomic investigation of changes in human vastus lateralis muscle in response to interval-exercise training. Proteomics 2009;9:5155-74.

[60] Burgomaster KA, Howarth KR, Phillips SM, Rakobowchuk M, Macdonald MJ, McGee SL, et al. Similar metabolic adaptations during exercise after low volume sprint interval and traditional endurance training in humans. J Physiol 2008;586:151-60.

[61] Burniston JG. Changes in the rat skeletal muscle proteome induced by moderate-intensity endurance exercise. Biochim Biophys Acta 2008;1784:1077-86.

[62] Takahashi M, Kubota S. Exercise-related novel gene is involved in myoblast differentiation. Biomed Res 2005;26:79-85.

[63] Guelfi KJ, Casey TM, Giles JJ, Fournier PA, Arthur PG. A proteomic analysis of the acute effects of high-intensity exercise on skeletal muscle proteins in fasted rats. Clin Exp Pharmacol Physiol 2006;33:952-7.

[64] Gandra PG, Valente RH, Perales J, Pacheco AG, Macedo DV. Proteomic analysis of rat skeletal muscle submitted to one bout of incremental exercise. Scand J Med Sci Sports 2010 (Electronic publication ahead of print).

[65] Yamaguchi W, Fujimoto E, Higuchi M, Tabata I. A DIGE proteomic analysis for high-intensity exercise-trained rat skeletal muscle. J Biochem 2010;148:327-33.

[66] Donoghue P, Doran P, Wynne K, Pedersen K, Dunn MJ, Ohlendieck K. Proteomic profiling of chronic low-frequency stimulated fast muscle. Proteomics 2007;7:3417-30.

[67] Janssen I, Heymsfield SB, Wang ZM, Ross R. Skeletal muscle mass and distribution in 468 men and women aged 18-88 yr. J Appl Physiol 2000;89:81-8.

[68] Kent-Braun JA, Ng AV. Specific strength and voluntary muscle activation in young and elderly women and men. J Appl Physiol 1999;87:22-9.

[69] Narici MV, Reeves ND, Morse CI, Maganaris CN. Muscular adaptations to resistance exercise in the elderly. J Musculoskelet Neuronal Interact 2004;4:161-4.

[70] Larsson L, Li X, Frontera WR. Effects of aging on shortening velocity and myosin isoform composition in single human skeletal muscle cells. Am J Physiol 1997;272:C638-49.

[71] Trappe S, Gallagher P, Harber M, Carrithers J, Fluckey J, Trappe T. Single muscle fibre contractile properties in young and old men and women. J Physiol 2003;552:47-58.

[72] Lexell J. Human aging, muscle mass, and fiber type composition. J Gerontol A Biol Sci Med Sci 1995;50 Spec No:11-6.

[73] Aoyagi Y, Shephard RJ. Aging and muscle function. Sports Med 1992;14:376-96.

[74] Coggan AR, Spina RJ, Rogers MA, King DS, Brown M, Nemeth PM, et al. Histochemical and enzymatic characteristics of skeletal muscle in master athletes. J Appl Physiol 1990;68: 1896-901.

[75] Frontera WR, Hughes VA, Fielding RA, Fiatarone MA, Evans WJ, Roubenoff R. Aging of skeletal muscle: a 12-yr longitudinal study. J Appl Physiol 2000;88:1321-6.

[76] Marx JO, Kraemer WJ, Nindl BC, Larsson L. Effects of aging on human skeletal muscle myosin heavy-chain mRNA content and protein isoform expression. J Gerontol A Biol Sci Med Sci 2002;57:B232-8.

[77] Balagopal P, Schimke JC, Ades P, Adey D, Nair KS. Age effect on transcript levels and synthesis rate of muscle MHC and response to resistance exercise. Am J Physiol Endocrinol Metab 2001;280:E203-8.
[78] Terman A, Brunk UT. Lipofuscin: mechanisms of formation and increase with age. APMIS 1998;106:265-76.

[79] Wang ZM, Messi ML, Delbono O. L-Type Ca(2+) channel charge movement and intracellular $\mathrm{Ca}(2+)$ in skeletal muscle fibers from aging mice. Biophys J 2000;78:1947-54.

[80] Boffoli D, Scacco SC, Vergari R, Solarino G, Santacroce G, Papa $\mathrm{S}$. Decline with age of the respiratory chain activity in human skeletal muscle. Biochim Biophys Acta 1994;1226:73-82.

[81] Sweeney HL, Bowman BF, Stull JT. Myosin light chain phosphorylation in vertebrate striated muscle: regulation and function. Am J Physiol 1993;264:C1085-95.

[82] Davis JS, Satorius CL, Epstein ND. Kinetic effects of myosin regulatory light chain phosphorylation on skeletal muscle contraction. Biophys J 2002;83:359-70.

[83] Szczesna D, Zhao J, Jones M, Zhi G, Stull J, Potter JD. Phosphorylation of the regulatory light chains of myosin affects Ca2+ sensitivity of skeletal muscle contraction. J Appl Physiol 2002;92:1661-70.

[84] Godt RE, Nosek TM. Changes of intracellular milieu with fatigue or hypoxia depress contraction of skinned rabbit skeletal and cardiac muscle. J Physiol 1989;412:155-80.

[85] Short KR, Bigelow ML, Kahl J, Singh R, Coenen-Schimke J, Raghavakaimal S, et al. Decline in skeletal muscle mitochondrial function with aging in humans. Proc Natl Acad Sci USA 2005;102:5618-23.

[86] Doran P, Donoghue P, O'Connell K, Gannon J, Ohlendieck K. Proteomics of skeletal muscle aging. Proteomics 2009;9: 989-1003.

[87] Capitanio D, Vasso M, Fania C, Moriggi M, Vigano A, Procacci $\mathrm{P}$, et al. Comparative proteomic profile of rat sciatic nerve and gastrocnemius muscle tissues in ageing by 2-D DIGE. Proteomics 2009;9:2004-20.

[88] Moriggi M, Vasso M, Fania C, Capitanio D, Bonifacio G, Salanova $\mathrm{M}$, et al. Long term bed rest with and without vibration exercise countermeasures: effects on human muscle protein dysregulation. Proteomics 2010;10: 3756-74.

[89] Gong H, Hatch V, Ali L, Lehman W, Craig R, Tobacman LS. Mini-thin filaments regulated by troponin-tropomyosin. Proc Natl Acad Sci USA 2005;102:656-61.

[90] Udaka J, Ohmori S, Terui T, Ohtsuki I, Ishiwata S, Kurihara S, et al. Disuse-induced preferential loss of the giant protein titin depresses muscle performance via abnormal sarcomeric organization. J Gen Physiol 2008;131:33-41.

[91] Hoshijima M. Mechanical stress-strain sensors embedded in cardiac cytoskeleton: $\mathrm{Z}$ disk, titin, and associated structures. Am J Physiol Heart Circ Physiol 2006;290:H1313-25.

[92] Isfort RJ, Wang F, Greis KD, Sun Y, Keough TW, Farrar RP, et al. Proteomic analysis of rat soleus muscle undergoing hindlimb suspension-induced atrophy and reweighting hypertrophy. Proteomics 2002;2:543-50.

[93] Isfort RJ, Wang F, Greis KD, Sun Y, Keough TW, Bodine SC, et al. Proteomic analysis of rat soleus and tibialis anterior muscle following immobilization. J Chromatogr B Analyt Technol Biomed Life Sci 2002;769:323-32.

[94] Seo Y, Lee K, Park K, Bae K, Choi I. A proteomic assessment of muscle contractile alterations during unloading and reloading. J Biochem 2006;139:71-80.

[95] Moriggi M, Cassano P, Vasso M, Capitanio D, Fania C, Musicco C, et al. A DIGE approach for the assessment of rat soleus muscle changes during unloading: effect of acetyl-Lcarnitine supplementation. Proteomics 2008;8:3588-604.

[96] Sorichter S, Puschendorf B, Mair J. Skeletal muscle injury induced by eccentric muscle action: muscle proteins as markers of muscle fiber injury. Exerc Immunol Rev 1999;5: 5-21.

[97] Sietsema KE, Meng F, Yates NA, Hendrickson RC, Liaw A, Song $\mathrm{Q}$ et al. Potential biomarkers of muscle injury after eccentric exercise. Biomarkers 2010;15:249-58. 
[98] Meng F, Wiener MC, Sachs JR, Burns C, Verma P, Paweletz CP, et al. Quantitative analysis of complex peptide mixtures using FTMS and differential mass spectrometry. J Am Soc Mass Spectrom 2007;18:226-33.

[99] Zhang H, Li XJ, Martin DB, Aebersold R. Identification and quantification of $\mathrm{N}$-linked glycoproteins using hydrazide chemistry, stable isotope labeling and mass spectrometry. Nat Biotechnol 2003;21:660-6.

[100] Zhang H, Yi EC, Li XJ, Mallick P, Kelly-Spratt KS, Masselon CD, et al. High throughput quantitative analysis of serum proteins using glycopeptide capture and liquid chromatography mass spectrometry. Mol Cell Proteomics 2005;4:144-55.

[101] Alagaratnam S, Mertens BJ, Dalebout JC, Deelder AM, van Ommen GJ, den Dunnen JT, et al. Serum protein profiling in mice: identification of Factor XIIIa as a potential biomarker for muscular dystrophy. Proteomics 2008;8:1552-63.

[102] Doran P, Martin G, Dowling P, Jockusch H, Ohlendieck K. Proteome analysis of the dystrophin-deficient MDX diaphragm reveals a drastic increase in the heat shock protein cvHSP. Proteomics 2006;6:4610-21.

[103] De Palma S, Morandi L, Mariani E, Begum S, Cerretelli P, Wait R, et al. Proteomic investigation of the molecular pathophysiology of dysferlinopathy. Proteomics 2006;6: 379-85.

[104] Campanaro S, Romualdi C, Fanin M, Celegato B, Pacchioni B, Trevisan S, et al. Gene expression profiling in dysferlinopathies using a dedicated muscle microarray. Hum Mol Genet 2002;11:3283-98.

[105] Liu J, Aoki M, Illa I, Wu C, Fardeau M, Angelini C, et al. Dysferlin, a novel skeletal muscle gene, is mutated in Miyoshi myopathy and limb girdle muscular dystrophy. Nat Genet 1998;20:31-6.

[106] Tagawa K, Ogawa M, Kawabe K, Yamanaka G, Matsumura T, Goto K, et al. Protein and gene analyses of dysferlinopathy in a large group of Japanese muscular dystrophy patients. J Neurol Sci 2003;211:23-8.

[107] Bansal D, Miyake K, Vogel SS, Groh S, Chen CC, Williamson R, et al. Defective membrane repair in dysferlin-deficient muscular dystrophy. Nature 2003;423:168-72.

[108] Cenacchi G, Fanin M, De Giorgi LB, Angelini C. Ultrastructural changes in dysferlinopathy support defective membrane repair mechanism. J Clin Pathol 2005;58:190-5.

[109] Sjoblom B, Salmazo A, Djinovic-Carugo K. Alpha-actinin structure and regulation. Cell Mol Life Sci 2008;65:2688-701.

[110] Ono S. Regulation of actin filament dynamics by actin depolymerizing factor/cofilin and actin-interacting protein 1: new blades for twisted filaments. Biochemistry 2003;42: 13363-70.

[111] Lemmers RJ, van der Vliet PJ, Klooster R, Sacconi S, Camano P, Dauwerse JG, et al. A unifying genetic model for facioscapulohumeral muscular dystrophy. Science 2010;329: 1650-3.

[112] Saneyoshi T, Kume S, Amasaki Y, Mikoshiba K. The Wnt/calcium pathway activates NF-AT and promotes ventral cell fate in Xenopus embryos. Nature 2002;417:295-9.

[113] Hosoda T, Monzen K, Hiroi Y, Oka T, Takimoto E, Yazaki Y, et al. A novel myocyte-specific gene Midori promotes the differentiation of P19CL6 cells into cardiomyocytes. J Biol Chem 2001;276:35978-89.

[114] Li J, Yin C, Okamoto H, Jaffe H, Oldfield EH, Zhuang Z, et al. Proteomic analysis of inclusion body myositis. J Neuropathol Exp Neurol 2006;65:826-33.

[115] Banwell BL, Engel AG. AlphaB-crystallin immunolocalization yields new insights into inclusion body myositis. Neurology 2000;54:1033-41.

[116] Hutchinson DO, Jongbloed B. Two-dimensional gel electrophoresis in inclusion body myositis. J Clin Neurosci 2008;15:440-4.
[117] Parker KC, Kong SW, Walsh RJ, Salajegheh M, Moghadaszadeh B, Amato AA, et al. Fast-twitch sarcomeric and glycolytic enzyme protein loss in inclusion body myositis. Muscle Nerve 2009;39:739-53.

[118] Parker KC, Patterson D, Williamson B, Marchese J, Graber A, He F, et al. Depth of proteome issues: a yeast isotope-coded affinity tag reagent study. Mol Cell Proteomics 2004;3:625-59.

[119] Jin S, Daly DS, Springer DL, Miller JH. The effects of shared peptides on protein quantitation in label-free proteomics by LC/MS/MS. J Proteome Res 2008;7:164-9.

[120] Huang Y, de Morree A, van Remoortere A, Bushby K, Frants RR, Dunnen JT, et al. Calpain 3 is a modulator of the dysferlin protein complex in skeletal muscle. Hum Mol Genet 2008;17:1855-66.

[121] Park JH, Niermann KJ, Ryder NM, Nelson AE, Das A, Lawton AR, et al. Muscle abnormalities in juvenile dermatomyositis patients: P-31 magnetic resonance spectroscopy studies. Arthritis Rheum 2000;43:2359-67.

[122] Rockerbie NR, Woo TY, Callen JP, Giustina T. Cutaneous changes of dermatomyositis precede muscle weakness. J Am Acad Dermatol 1989;20:629-32.

[123] Salajegheh M, Kong SW, Pinkus JL, Walsh RJ, Liao A, Nazareno R, et al. Interferon-stimulated gene 15 (ISG15) conjugates proteins in dermatomyositis muscle with perifascicular atrophy. Ann Neurol 2010;67:53-63.

[124] Walsh RJ, Kong SW, Yao Y, Jallal B, Kiener PA, Pinkus JL, et al. Type I interferon-inducible gene expression in blood is present and reflects disease activity in dermatomyositis and polymyositis. Arthritis Rheum 2007;56:3784-92.

[125] Yuan W, Krug RM. Influenza B virus NS1 protein inhibits conjugation of the interferon (IFN)-induced ubiquitin-like ISG15 protein. EMBO J 2001;20:362-71.

[126] Zhao C, Beaudenon SL, Kelley ML, Waddell MB, Yuan W, Schulman BA, et al. The UbcH8 ubiquitin E2 enzyme is also the E2 enzyme for ISG15, an IFN-alpha/beta-induced ubiquitin-like protein. Proc Natl Acad Sci USA 2004;101: 7578-82.

[127] Dastur A, Beaudenon S, Kelley M, Krug RM, Huibregtse JM. Herc5, an interferon-induced HECT E3 enzyme, is required for conjugation of ISG15 in human cells. J Biol Chem 2006;281:4334-8.

[128] Malakhov MP, Malakhova OA, Kim KI, Ritchie KJ, Zhang DE. UBP43 (USP18) specifically removes ISG15 from conjugated proteins. J Biol Chem 2002;277:9976-81.

[129] Desai SD, Haas AL, Wood LM, Tsai YC, Pestka S, Rubin EH, et al. Elevated expression of ISG15 in tumor cells interferes with the ubiquitin/26S proteasome pathway. Cancer Res 2006;66:921-8.

[130] Beck-Nielsen H. Mechanisms of insulin resistance in non-oxidative glucose metabolism: the role of glycogen synthase. J Basic Clin Physiol Pharmacol 1998;9:255-79.

[131] Eriksson J, Franssila-Kallunki A, Ekstrand A, Saloranta C, Widen E, Schalin C, et al. Early metabolic defects in persons at increased risk for non-insulin-dependent diabetes mellitus. N Engl J Med 1989;321:337-43.

[132] Damsbo P, Vaag A, Hother-Nielsen O, Beck-Nielsen H. Reduced glycogen synthase activity in skeletal muscle from obese patients with and without type 2 (non-insulindependent) diabetes mellitus. Diabetologia 1991;34:239-45.

[133] Kelley DE, He J, Menshikova EV, Ritov VB. Dysfunction of mitochondria in human skeletal muscle in type 2 diabetes. Diabetes 2002;51:2944-50.

[134] Gebhart SS, Shoffner JM, Koontz D, Kaufman A, Wallace D. Insulin resistance associated with maternally inherited diabetes and deafness. Metabolism 1996;45:526-31.

[135] Wallace DC. Mitochondrial diseases in man and mouse. Science 1999;283:1482-8.

[136] Anderson CM. Achieving breastfeeding success. Simple solutions to common concerns. Adv Nurse Pract 1999;7:67-9. 
[137] Antonetti DA, Reynet C, Kahn CR. Increased expression of mitochondrial-encoded genes in skeletal muscle of humans with diabetes mellitus. J Clin Invest 1995;95:1383-8.

[138] Winder WW, Hardie DG. AMP-activated protein kinase, a metabolic master switch: possible roles in type 2 diabetes. Am J Physiol 1999;277:E1-E10.

[139] Winder WW, Holmes BF, Rubink DS, Jensen EB, Chen M, Holloszy JO. Activation of AMP-activated protein kinase increases mitochondrial enzymes in skeletal muscle. J Appl Physiol 2000;88:2219-26.

[140] Michael LF, Wu Z, Cheatham RB, Puigserver P, Adelmant G, Lehman JJ, et al. Restoration of insulin-sensitive glucose transporter (GLUT4) gene expression in muscle cells by the transcriptional coactivator PGC-1. Proc Natl Acad Sci USA 2001;98:3820-5.

[141] Wu Z, Puigserver P, Andersson U, Zhang C, Adelmant G, Mootha $\mathrm{V}$, et al. Mechanisms controlling mitochondrial biogenesis and respiration through the thermogenic coactivator PGC-1. Cell 1999;98:115-24.

[142] He J, Watkins S, Kelley DE. Skeletal muscle lipid content and oxidative enzyme activity in relation to muscle fiber type in type 2 diabetes and obesity. Diabetes 2001;50:817-23.
[143] Hwang H, Bowen BP, Lefort N, Flynn CR, De Filippis EA, Roberts C, et al. Proteomics analysis of human skeletal muscle reveals novel abnormalities in obesity and type 2 diabetes. Diabetes 2010;59:33-42.

[144] Johnson DT, Harris RA, French S, Aponte A, Balaban RS. Proteomic changes associated with diabetes in the BB-DP rat. Am J Physiol Endocrinol Metab 2009;296:E422-32.

[145] Mullen E, Ohlendieck K. Proteomic profiling of non-obese type 2 diabetic skeletal muscle. Int J Mol Med 2010;25:445-58.

[146] Kitahara A, Toyota T, Kakizaki M, Goto Y. Activities of hepatic enzymes in spontaneous diabetes rats produced by selective breeding of normal Wistar rats. Tohoku J Exp Med 1978;126:7-11.

[147] Hahm JR, Ahn JS, Noh HS, Baek SM, Ha JH, Jung TS, et al. Comparative analysis of fat and muscle proteins in fenofibrate-fed type II diabetic OLETF rats: the fenofibratedependent expression of PEBP or C11orf59 protein. BMB Rep 2010;43:337-43. 